\title{
Influence of the quasi-biennial oscillation on the extratropical winter stratosphere in an atmospheric general circulation model and in reanalysis data
}

Article

Published Version

Anstey, J. A., Shepherd, T. G. and Scinocca, J. F. (2010) Influence of the quasi-biennial oscillation on the extratropical winter stratosphere in an atmospheric general circulation model and in reanalysis data. Journal of the Atmospheric Sciences, 67 (5). pp. 1402-1419. ISSN 1520-0469 doi: https://doi.org/10.1175/2009JAS3292.1 Available at https://centaur.reading.ac.uk/31619/

It is advisable to refer to the publisher's version if you intend to cite from the work. See Guidance on citing.

To link to this article DOI: http://dx.doi.org/10.1175/2009JAS3292.1

Publisher: American Meteorological Society

All outputs in CentAUR are protected by Intellectual Property Rights law, including copyright law. Copyright and IPR is retained by the creators or other copyright holders. Terms and conditions for use of this material are defined in the End User Agreement. 


\section{www.reading.ac.uk/centaur}

\section{CentAUR}

Central Archive at the University of Reading

Reading's research outputs online 


\title{
Influence of the Quasi-Biennial Oscillation on the Extratropical Winter Stratosphere in an Atmospheric General Circulation Model and in Reanalysis Data
}

\author{
JAMES A. ANSTEY* AND THEOdore G. SHEPHERD \\ Department of Physics, University of Toronto, Toronto, Ontario, Canada \\ JOHN F. SCINOCCA \\ Canadian Centre for Climate Modelling and Analysis, University of Victoria, Victoria, British Columbia, Canada
}

(Manuscript received 20 August 2009, in final form 18 November 2009)

\begin{abstract}
The interannual variability of the stratospheric polar vortex during winter in both hemispheres is observed to correlate strongly with the phase of the quasi-biennial oscillation (QBO) in tropical stratospheric winds. It follows that the lack of a spontaneously generated QBO in most atmospheric general circulation models (AGCMs) adversely affects the nature of polar variability in such models. This study examines QBO-vortex coupling in an AGCM in which a QBO is spontaneously induced by resolved and parameterized waves.

The QBO-vortex coupling in the AGCM compares favorably to that seen in reanalysis data [from the 40-yr ECMWF Re-Analysis (ERA-40)], provided that careful attention is given to the definition of QBO phase. A phase angle representation of the QBO is employed that is based on the two leading empirical orthogonal functions of equatorial zonal wind vertical profiles. This yields a QBO phase that serves as a proxy for the vertical structure of equatorial winds over the whole depth of the stratosphere and thus provides a means of subsampling the data to select QBO phases with similar vertical profiles of equatorial zonal wind. Using this subsampling, it is found that the QBO phase that induces the strongest polar vortex response in early winter differs from that which induces the strongest late-winter vortex response. This is true in both hemispheres and for both the AGCM and ERA-40.

It follows that the strength and timing of QBO influence on the vortex may be affected by the partial seasonal synchronization of QBO phase transitions that occurs both in observations and in the model. This provides a mechanism by which changes in the strength of QBO-vortex correlations may exhibit variability on decadal time scales. In the model, such behavior occurs in the absence of external forcings or interannual variations in sea surface temperatures.
\end{abstract}

\section{Introduction}

During winter in either hemisphere, the stratospheric polar vortex is episodically disturbed by tropospherically forced planetary waves, leading to interannual variability in the strength of the vortex. Northern Hemisphere $(\mathrm{NH})$ winter exhibits stronger variability than Southern Hemisphere $(\mathrm{SH})$ winter because planetary wave amplitudes are larger in the NH. In both hemispheres, the interannual

* Additional affiliation: University of Victoria, Victoria, British Columbia, Canada.

Corresponding author address: James A. Anstey, Canadian Centre for Climate Modelling and Analysis, University of Victoria, P.O. Box 3065, STN CSC, Victoria, BC V8W 3V6, Canada.

E-mail: janstey@atmosp.physics.utoronto.ca variability of the polar vortex is observed to correlate strongly with the phase of the quasi-biennial oscillation (QBO) in tropical stratospheric zonal winds.

A strong correlation between QBO phase and $\mathrm{NH}$ polar vortex strength was first reported by Holton and Tan (1980) and is often referred to as the Holton-Tan effect. Using a 16-yr record, they found the $\mathrm{NH}$ winter polar vortex to be stronger and the polar cap colder when $50-\mathrm{hPa}$ equatorial winds were westerly, whereas easterly 50-hPa equatorial winds coincided with a weaker and warmer vortex. They hypothesized the cause of this coupling to be modulation by the QBO of the position of the low-latitude line of zero zonal-mean zonal wind, $\bar{u}=0$, which is a critical surface for the stationary planetary waves that dominate the forcing of the $\mathrm{NH}$ winter stratospheric zonal-mean flow. The modulation of $\mathrm{NH}$ vortex strength by QBO phase was found to occur in both 
early (November-December) and late (January-March) winter, with high statistical significance in both cases. Subsequent studies confirmed their findings (Dunkerton and Baldwin 1991; Naito and Hirota 1997; Lu et al. 2008) but tended to find that the strength and statistical significance of the NH late-winter QBO-vortex correlation was reduced when longer records were considered. For the SH, early studies of Antarctic ozone depletion hypothesized that QBO influence might underlie an apparent biennial modulation of October minimum ozone values (Garcia and Solomon 1987). Later studies, with the benefit of an extended observational record, have upheld the existence of QBO-vortex coupling in the SH (Baldwin and Dunkerton 1998; Hitchman and Huesmann 2009).

Fluctuations in the nature of the NH late-winter QBOvortex coupling have been attributed to the 11-yr solar cycle (Labitzke 1987; Labitzke and van Loon 1988; Naito and Hirota 1997). During solar minima, the polar vortex appears to respond to QBO phase in the manner found by Holton and Tan (1980), whereas during solar maxima the vortex response appears to be either reversed or absent (Gray et al. 2001b). It has been suggested that this behavior is caused by the effect of anomalous solar heating on the meridional temperature gradient in the stratosphere, which affects the zonal-mean zonal wind and hence the propagation and dissipation of planetaryscale waves (Kodera 1991). However, Lu et al. (2008) found that the running correlation of QBO phase and $\mathrm{NH}$ vortex strength weakened during the 1977-97 period, which equally samples both solar cycle phases. The question of what determines decadal-time scale fluctuations of the late-winter QBO-vortex coupling remains unresolved.

The effect of QBO phase on the winter polar vortex has been the subject of numerous modeling studies employing both mechanistic models and atmospheric general circulation models (AGCMs). Mechanistic studies with primitive equation models have considered various idealized forms of tropical zonal wind perturbations. Early studies tended to impose simplified one-layer tropical perturbations to investigate the first-order response of the vortex to the tropical wind state (Bridger 1984; Holton and Austin 1991; O'Sullivan and Young 1992; O'Sullivan and Dunkerton 1994). Later studies have explored the effect of varying the altitude of the imposed tropical wind perturbation, finding that altitudes above $10 \mathrm{hPa}$ may influence the vortex (Gray et al. 2001a; Gray 2003; Gray et al. 2003, 2004). The effect of systematically varying the seasonal alignment of QBO phase has also been considered (Hampson and Haynes 2006; Naito and Yoden 2006). Mechanistic studies have generally found that the polar vortex is sensitive to the tropical wind state for an intermediate range of extratropical planetary wave amplitudes, whereas no such sensitivity exists when planetary wave amplitudes are either very large or very small. Similar conclusions have been reached using single-layer mechanistic models (O'Sullivan and Salby 1990; Chen 1996; O'Sullivan 1997). Mechanistic studies have mainly considered the relation between the tropical wind state and the occurrence of sudden stratospheric warmings (SSWs) and thus have focused on the NH polar vortex response to QBO phase. The question of which QBO altitudes are causally most important for the polar vortex response remains open, as the mechanistic studies have reached no consensus on this issue. [Since the QBO is periodic in altitude, observations alone cannot answer this question. If the QBO-vortex correlation is positive for one choice of QBO altitude, it will be negative for another choice of QBO altitude, and hence observations do not provide a clear test of the Holton and Tan (1980) hypothesis that equatorial westerlies are associated with a colder, stronger polar vortex.]

Studies of QBO extratropical influence with AGCMs have employed either spontaneous QBOs, which are forced by a combination of resolved and parameterized waves, or imposed QBOs. Since many AGCMs do not exhibit a spontaneous QBO, and because spontaneous QBOs may have unrealistic aspects, the latter method provides a useful means of examining the influence of a realistic QBO on the extratropical circulation. However, it does rule out the possibility of detecting any possible influence in the other direction (i.e., influence of the extratropical circulation on the QBO itself) and if the observed QBO is used, it may build in the effects of external forcings. AGCM studies may be further subdivided into those that have considered QBO extratropical influence as a mode of internal atmospheric variability and those that have also considered the explicit effect of external forcings such as the 11-yr solar cycle.

Considering QBO extratropical influence as internal atmospheric variability, Hamilton (1998) and Pascoe et al. (2006) used imposed QBOs and found the NH polar vortex to be affected by QBO phase in a sense similar to that observed. Hamilton (1998) did not find an earlywinter (November) QBO-vortex coupling; Pascoe et al. (2006) found a November coupling but only obtained a late-winter effect when the imposed QBO occupied a very deep $(15-65 \mathrm{~km})$ layer. Utilizing AGCMs with spontaneous QBOs, Niwano and Takahashi (1998) and Calvo et al. (2007) also found QBO-vortex couplings of realistic sign and magnitude although, like Hamilton (1998), neither study found a response during November, which is when the statistical significance of the observed QBO-vortex coupling is greatest (Dunkerton and Baldwin 1991). Hamilton (1998) also found that the spatial structure of QBO-extratropical correlations differed between 
the first 23 years and last 22 years of the model run, suggesting that a long record is required to obtain stable statistics of the QBO-vortex coupling. Considering QBO influence in the presence of the 11-yr solar cycle, Kodera et al. (1991) and Matthes et al. (2004) used imposed QBOs whereas Palmer and Gray (2005) used a spontaneous QBO. While all three studies showed behavior reminiscent of the observed QBO-solar cycle relationship found by Labitzke and van Loon (1988), only Matthes et al. (2004) did so using realistic solar irradiance changes.

The present study examines the extratropical influence of the QBO during both $\mathrm{NH}$ and $\mathrm{SH}$ winter in an AGCM as an internal mode of atmospheric variability, by which we mean that no external forcings (such as the 11-yr solar cycle) or interannual changes in sea surface temperatures (SSTs) are imposed. We quantify the seasonality and robustness of the QBO-vortex coupling as diagnosed from a long ( $150 \mathrm{yr})$ run of the AGCM. The QBO in the model is forced spontaneously by a combination of resolved and parameterized waves, which allows for the possibility of natural variability of QBO cycles and feedbacks from the extratropics on the QBO itself. The realism of QBO-vortex coupling in the AGCM is assessed by comparison of the model results with 40-yr European Centre for Medium-Range Weather Forecasts (ECMWF) Re-Analysis (ERA-40) data.

The plan of the paper is as follows: Section 2 describes the datasets used. Section 3 compares the modeled QBO with the QBO as observed by tropical radiosondes. Section 4 diagnoses the QBO-vortex coupling in the AGCM and in ERA-40. Section 5 discusses the results, with emphasis on the causality of QBO influence on the polar vortex, and a mechanism by which irregular decadal variability in QBO-vortex coupling may occur as a result of internal atmospheric variability. Conclusions are offered in section 6 .

\section{Data}

A 150-yr integration of the Canadian Middle Atmosphere Model (CMAM; Beagley et al. 1997; Scinocca et al. 2008) is employed. For the present study, the horizontal resolution is T47 and there are 98 vertical levels extending from the surface up to $0.01 \mathrm{hPa}(\approx 75 \mathrm{~km})$. The vertical resolution in the stratosphere is $\approx 0.5 \mathrm{~km}$ up to $10 \mathrm{hPa}(32 \mathrm{~km})$, after which it coarsens gradually to become $2-3 \mathrm{~km}$ in the lower mesosphere. Sea surface temperatures are prescribed from the Atmospheric Model Intercomparison Project II (AMIP II) climatology by interpolating the monthly means to generate a smooth time series of daily values; hence the SSTs vary seasonally but possess no interannual variability. Other sources of interannual variability, such as long-time scale radiative

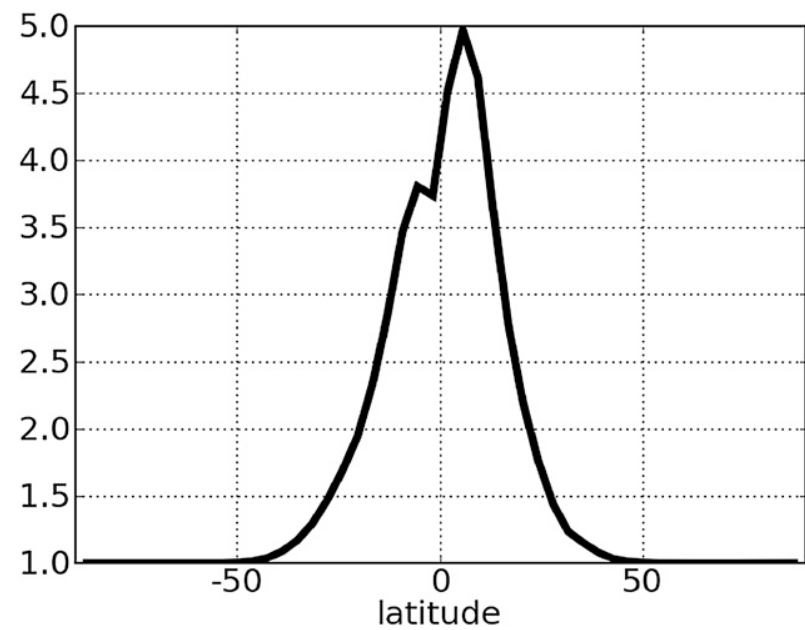

FIG. 1. Latitudinal enhancement of total NGWD launch spectrum momentum flux, based on the annual-mean precipitation generated by deep convection in the model. For display purposes, values are normalized by the magnitude of the momentum flux at high latitudes ( $\equiv 1.0)$.

forcings due to increases in greenhouse gas concentrations or 11-yr solar cycle variations, are also absent. Prognostic chemistry is not employed, and ozone concentrations are prescribed from a seasonally varying climatology.

The vertical resolution used here is finer than the resolution usually employed in CMAM. Most previous studies have found that high vertical resolution is required to spontaneously generate a QBO in an AGCM (e.g., Takahashi 1996; Horinouchi and Yoden 1998; Giorgetta et al. 2006). In addition, increased forcing at tropical latitudes by the parameterized nonorographic wave drag (NGWD) of Scinocca (2003) was also required before a QBO developed spontaneously in CMAM. In the usual model configuration, the NGWD launch spectrum momentum flux is specified to be uniform in latitude and longitude. For this study, we adopted a latitudinal dependence of the form shown in Fig. 1, which is based on the latitudinal profile of annual-mean precipitation generated by deep convection in the model. Physical plausibility for this tropical NGWD enhancement is based on the expectation that deep convection should generate large amounts of upward-propagating wave activity at scales unresolved by the model. Unfortunately, the NGWD launch spectrum is at present poorly constrained by observations, and thus our justification for the tropical NGWD enhancement must be regarded as primarily heuristic. It should be noted, however, that it is now generally accepted that some amount of gravity wave forcing is required to drive the real QBO (Dunkerton 1997).

Tropical radiosondes at near-equatorial stations have provided a valuable long-term record of QBO winds 


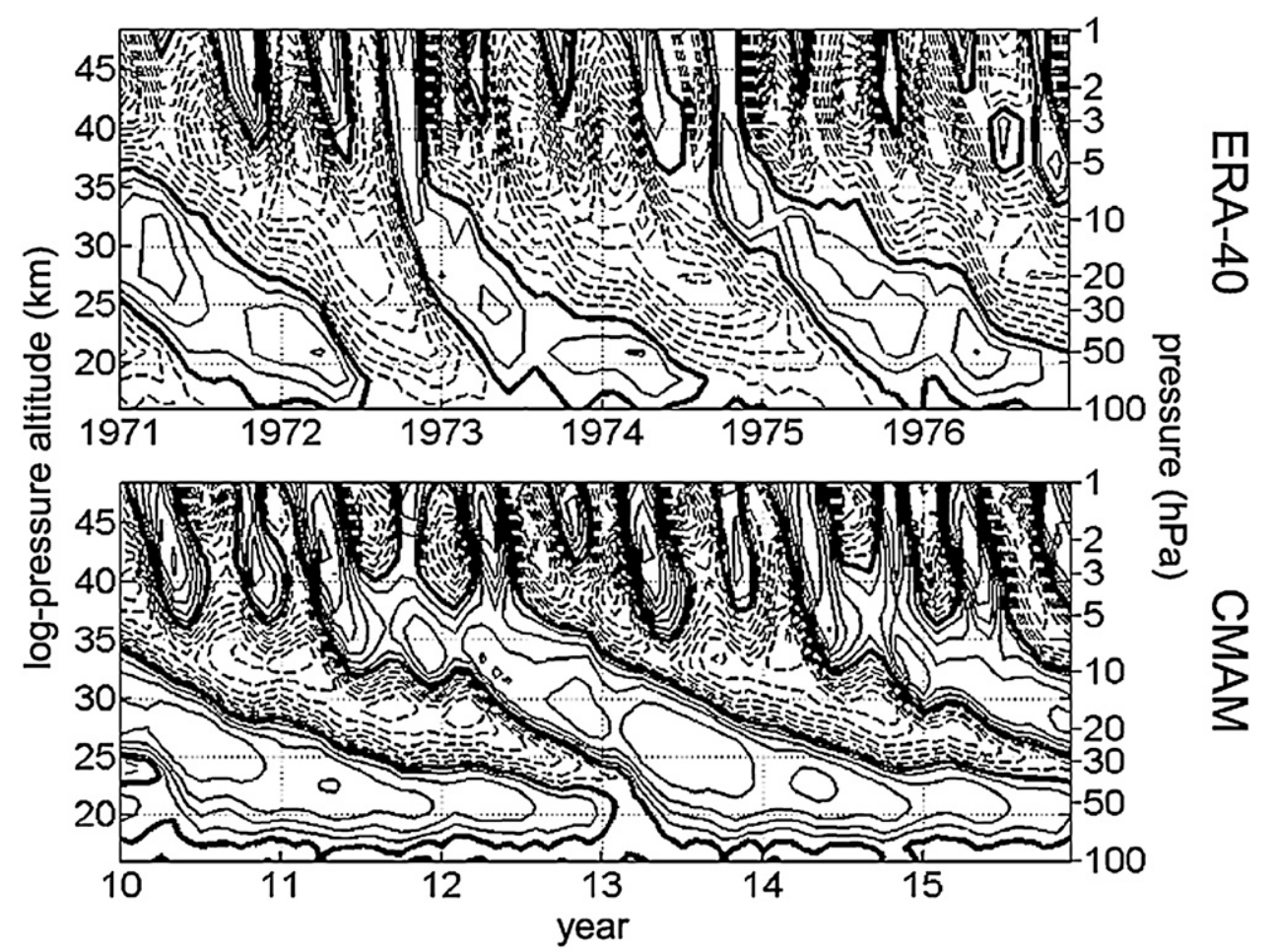

FIG. 2. Six-year excerpt of the QBO time series in (top) ERA-40 equatorial $\bar{u}$ and (bottom) CMAM $\bar{u}$ averaged over $2^{\circ} \mathrm{N}-2^{\circ} \mathrm{S}$ (the two CMAM latitudinal grid points closest to the equator). Left vertical axis shows $\log$-pressure altitude $z=-H \log \left(p / p_{0}\right)$ where $p=$ pressure, $p_{0}=1000 \mathrm{hPa}$, and $H=7 \mathrm{~km}$. Contour interval is $5 \mathrm{~m} \mathrm{~s}^{-1}$; negative contours are dashed, with the $\bar{u}=0$ line in thick black.

since 1953. The data were compiled into a contiguous record at the Freie Universität Berlin, using observations from three stations: Canton Island $\left(3^{\circ} \mathrm{S}, 172^{\circ} \mathrm{W}\right.$; January $1953-$ August 1967$)$, Gan-Maledives $\left(1^{\circ} \mathrm{S}, 73^{\circ} \mathrm{E}\right.$; September 1967-December 1975), and Singapore $\left(1^{\circ} \mathrm{N}\right.$, $104^{\circ} \mathrm{E}$; January 1976-present) (Naujokat 1986). The data are provided as monthly means at seven vertical levels (70, 50, 40, 30, 20, 15, and $10 \mathrm{hPa}$, covering the range 19$32 \mathrm{~km}$ ). Although the observations are made only at a single longitude, which changes over time, they are assumed to provide an adequate representation of the QBO on the grounds that zonal asymmetries in the lower stratospheric flow are believed to be small in the monthly means, a view which is supported by AGCM modeling results (Hamilton et al. 2004).

To study QBO-vortex coupling through the entire stratosphere, we examine the ERA-40 reanalysis Uppala et al. (2005). We employ monthly means of daily data that are publicly available on the ECMWF Web site (http://data-portal.ecmwf.int/data/d/era40_daily/levtype= $\mathrm{pl} /$ ) on 23 pressure levels that extend from $1000 \mathrm{hPa}$ (the surface) to $1 \mathrm{hPa}(50 \mathrm{~km})$ on a latitude-longitude grid of $2.5^{\circ} \times 2.5^{\circ}$ resolution. The upper stratosphere $(5-2-\mathrm{hPa}$ layer) suffers from a cold bias of $\sim 5 \mathrm{~K}$ in the later part of the record, and there is a large cold bias of $\sim 10 \mathrm{~K}$ during winter and spring in the Antarctic lower stratosphere during the early years of the record (Randel et al. 2004; Uppala et al. 2005). Since we do not examine trends in this study, it is the accuracy of interannual variability in ERA-40 that is of primary importance here. Uppala et al. (2005) argue that because of the extensive NH radiosonde coverage over the whole reanalysis period, ERA-40 gives an accurate representation of SSW events in both the presatellite (i.e., prior to 1979) and satellite eras. The ERA-40 representation of the QBO is also of high quality: up to $10 \mathrm{hPa}(32 \mathrm{~km})$ it agrees well with (and is strongly constrained by) the tropical radiosonde data (Randel et al. 2004), while agreement with tropical rocketsonde data is very good up to $3 \mathrm{hPa}$ (41 km) (Baldwin and Gray 2005).

\section{Characteristics of the modeled QBO}

Figure 2 shows 6-yr excerpts of the time series of tropical zonal-mean zonal wind $\bar{u}$ from (top) ERA-40 and (bottom) CMAM. It is apparent that the CMAM QBO has a westerly bias in the lower stratosphere below $25 \mathrm{~km}(30 \mathrm{hPa})$, as well as an unrealistically long period of $\sim 35$ months (the observed QBO period being $\sim 28$ months). Despite the westerly bias in the lowermost stratosphere, plots of deseasonalized $\bar{u}$ (not shown) 

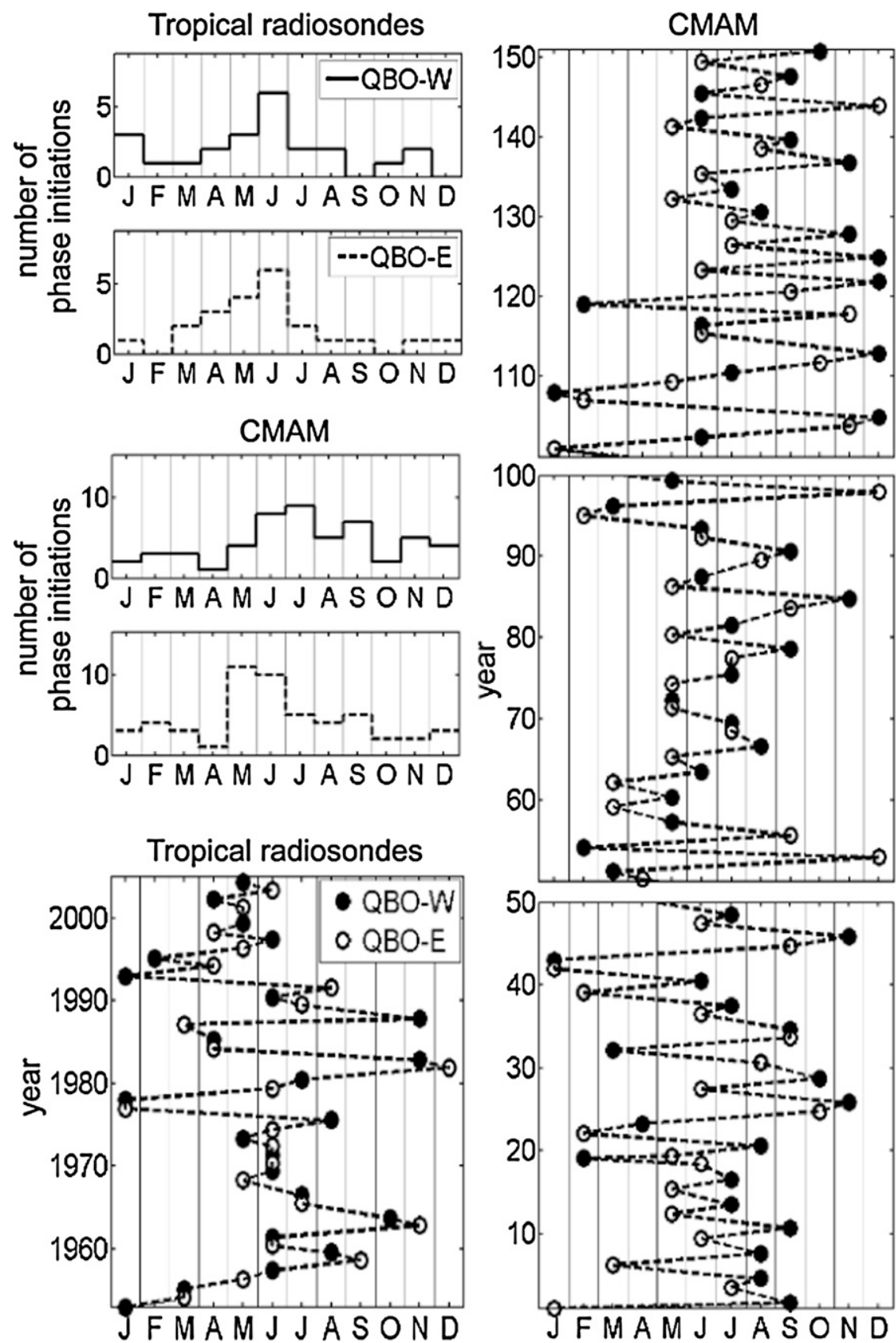

FIG. 3. Seasonal timing of $50-\mathrm{hPa}(z=21 \mathrm{~km})$ QBO phase initiations in monthly mean tropical radiosonde $u$ and CMAM $\bar{u}$ averaged over $2^{\circ} \mathrm{N}-2^{\circ} \mathrm{S}$. The 50 -hPa time series used to define the phase initiations was first deseasonalized (by subtracting the monthly climatology of the whole record) and a 5-month running mean was then applied. Histogram panels show the count of phase initiations, by month, for the whole record. The other panels show the time series of the same behavior (the histogram values represent the count of dots in each column); dashed lines connect consecutive QBO phases. The CMAM time series panels are broken at 50-yr intervals to help facilitate comparison with the 53-yr tropical radiosonde time series.

indicate that the 35-month periodicity extends down as far as $19 \mathrm{~km}(70 \mathrm{hPa})$.

While the CMAM QBO period of 35 months is close to 36 months, it does not lock to the annual cycle. Figure 3 shows the seasonal timing of QBO phase initiations at $50 \mathrm{hPa}(21 \mathrm{~km})$ in tropical radiosonde data and in CMAM. QBO phases are defined by the sign of monthly average deseasonalized equatorial $u$ (radiosondes) or $\bar{u}$ 

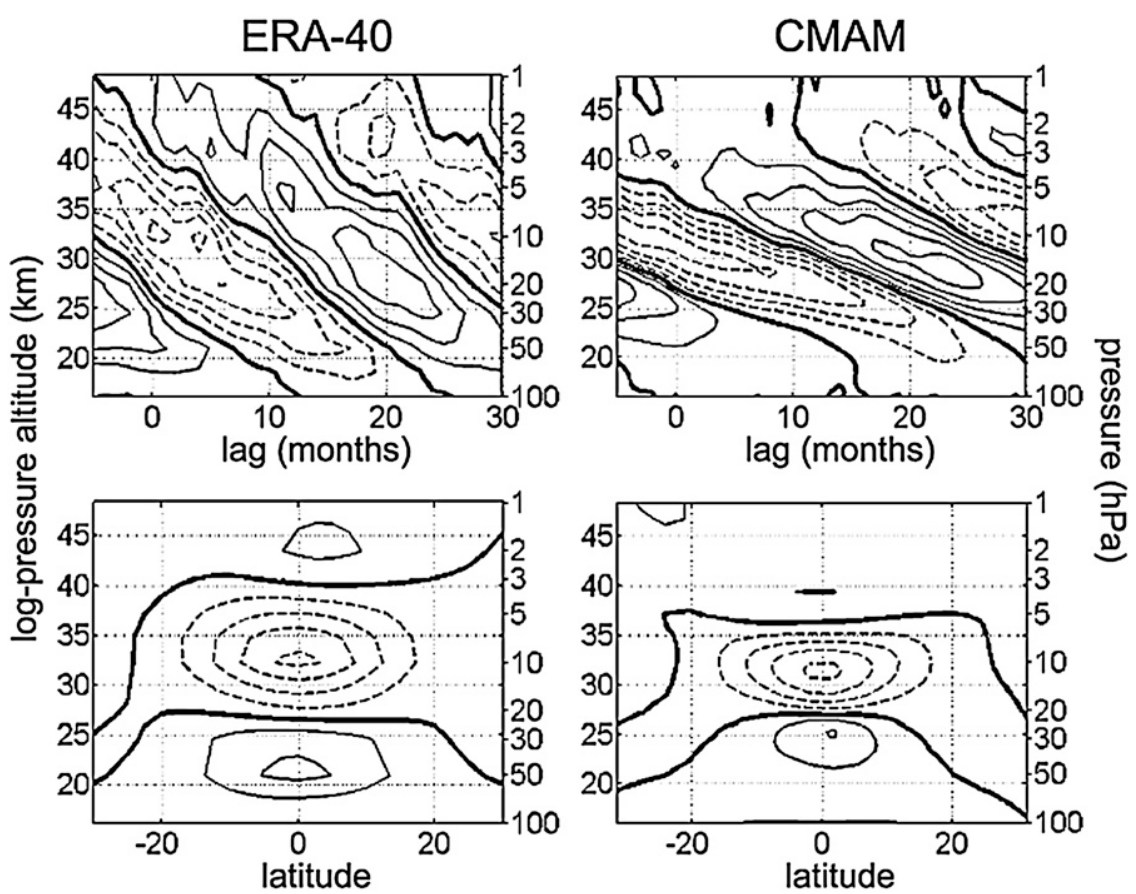

FIG. 4. Composites of deseasonalized $\bar{u}$, keyed to QBO-E initiations at $20 \mathrm{hPa}(z=27 \mathrm{~km})$, for (left) ERA-40 and (right) CMAM. (top) Altitude-time composites of $\bar{u}$ (ERA-40: equatorial $\bar{u}$; CMAM: $\bar{u}$ averaged over $2^{\circ} \mathrm{N}-2^{\circ} \mathrm{S}$ ). (bottom) Altitude-latitude composites for $\bar{u}$ at lag $=0$. Contours are as in Fig. 2.

(CMAM), where deseasonalization is performed by subtracting the climatology of the monthly averaged winds, and phase initiations are defined as the first month of a new QBO phase. It is evident from the histograms in Fig. 3 that a partial seasonal synchronization of QBO phase transitions occurs in the radiosonde data, consistent with Dunkerton (1990) and Baldwin et al. (2001), and similar behavior occurs in CMAM. The radiosonde time series in Fig. 3 indicates that the preferred seasonal timing of phase initiations tends to vary on a decadal time scale, inasmuch as some periods $(1965-75,1996-$ 2004) seem to favor phase initiation during a particular season, while others (1953-64, 1977-95) are characterized by a slow drift of phase initiations with respect to the annual cycle. The CMAM time series in Fig. 3 behaves similarly, albeit with a longer time scale for switching between regimes of clustering and drifting (e.g., years 65-90 for clustering and years $90-120$ for drifting); the longer time scale in CMAM is presumably due to the mean QBO period being longer and also close to a multiple of the annual cycle. The behavior shown in Fig. 3 is consistent with QBO phases having variable duration, since a constant QBO period would imply either a uniform drift of phase initiations with respect to the annual cycle or a consistently repeated seasonal timing of phase initiations. QBO phase initiations at altitudes above $50 \mathrm{hPa}$ also exhibit partial seasonal synchronization in both the radiosonde data and CMAM (not shown); we have chosen $50 \mathrm{hPa}$ for presentation because the seasonality is particularly strong at this altitude.

The partial seasonal synchronization of QBO phase initiations may be due in part to the seasonal cycle in tropical upwelling, since the tropical ascending branch of the Brewer-Dobson circulation opposes the descent of QBO phases and does so most strongly during NH winter (Dunkerton 1990, 1997). Seasonal variations in the strength of Kelvin and Rossby-gravity wave activity may also be important (Maruyama 1991), as may the stratopause semiannual oscillation as a possible initiator of a gravity wave-driven QBO (Lindzen and Holton 1968; Campbell and Shepherd 2005). It has also been suggested that decadal variations in QBO period are linked to the solar cycle (Salby and Callaghan 2000). Since our model contains no 11-yr solar cycle or any other external forcings with interannual time scales, nor any interannual variability in SSTs, the CMAM results shown in Fig. 3 demonstrate that these are not necessary conditions for the QBO to exhibit a variable period.

Figure 4 shows composites of monthly average deseasonalized $\bar{u}$, where lag $=0$ corresponds to the initiation of easterly QBO (QBO-E) phases at $20 \mathrm{hPa}(27 \mathrm{~km})$ for ERA-40 and CMAM. Figure 4 indicates that the 
CMAM QBO has realistic peak amplitude but that its vertical extent is reduced in comparison to ERA-40, as is its meridional width in the lower stratosphere. However, the meridional width in the middle stratosphere is realistic.

\section{QBO-vortex coupling}

\section{a. Methodology}

The method most commonly used to diagnose QBO influence on the extratropical circulation, which is the method employed in this section, is to composite years according to QBO phase and take the difference of the composites. Grouping years in this fashion requires an objective definition of QBO phase. The most straightforward choice is to pick a single QBO altitude (e.g., $40 \mathrm{hPa}$ ) and group years according to whether the equatorial zonal wind, $\bar{u}_{\mathrm{EQ}}$ is westerly or easterly at that altitude (Holton and Tan 1980; Dunkerton and Baldwin 1991; Naito and Hirota 1997; Lu et al. 2008). The same approach has also been used with shear indices, that is, $\partial \bar{u}_{\mathrm{EQ}} / \partial z$ (Huesmann and Hitchman 2001; Hitchman and Huesmann 2009). Another method is to decompose the vertically varying $\bar{u}_{\mathrm{EO}}(z)$ into empirical orthogonal functions (EOFs) and define a phase angle based on the two leading modes (Wallace et al. 1993; Baldwin and Dunkerton 1998). An advantage of this method is that it accounts for QBO vertical structure over a range of altitudes and is thus a more suitable proxy for the vertical profile of $\bar{u}_{\mathrm{EQ}}(z)$ than is a single-level QBO phase definition. This method has been used in studies of QBOinduced variability in ozone (Randel and Wu 1996; Logan et al. 2003).

The EOF expansion is defined by expressing $\bar{u}_{\mathrm{EQ}}$ as

$$
\bar{u}_{\mathrm{EQ}}(z, t)=\sum_{i=1}^{n} F_{i}(z) P_{i}(t),
$$

with $F_{i}(z)$ being the EOFs and $P_{i}(t)$ the principal component time series. The $F_{i}(z)$ are the eigenvectors of the $n \times n$ covariance matrix $\mathbf{C}$ of the time series $\bar{u}_{\mathrm{EQ}}(z, t)$ where $n$ is the number of vertical levels (von Storch and Zwiers 1999). Prior to calculation of $\mathbf{C}, \bar{u}_{\mathrm{EQ}}(z, t)$ is deseasonalized and then smoothed with a 5-month running mean (as was done in section 3). For any reasonable choice of vertical levels that captures the QBO (e.g., the altitude range of the tropical radiosonde data), the two leading EOF modes $i=(1,2)$ capture roughly $95 \%$ of the variance of the smoothed time series $\bar{u}_{\mathrm{EQ}}(z, t)$. Since $F_{i}$ and $F_{j}$ are orthogonal for $i \neq j$, the $P_{i}(t)$ represent projections of $\bar{u}_{\mathrm{EQ}}(z, t)$ onto the spatial patterns $F_{i}(z)$. Following Wallace et al. (1993), we may treat the time a)

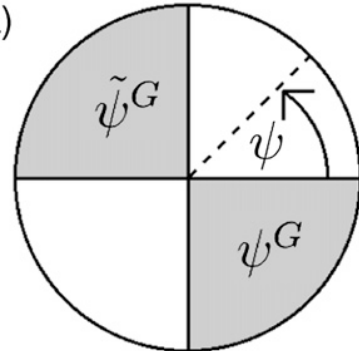

b)

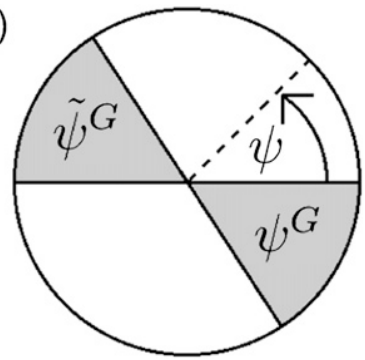

FIG. 5. Schematic illustration of the compositing technique based on $\mathrm{QBO}$ phase angle $\psi$. One orbit around the circle represents one full QBO cycle. The shaded regions represent particular choices of $\psi^{G}-\tilde{\psi}^{G}$ pairs: (a) $\Delta \psi^{G}=0.25$, with $\psi^{G} \equiv[-0.25,0]$ and $\tilde{\psi}^{G} \equiv$ $[0.25,0.5]$; (b) $\Delta \psi^{G}=0.15$, with $\psi^{G} \equiv[-0.15,0]$ and $\tilde{\psi}^{G} \equiv[0.35,0.5]$. We search for the strongest extratropical QBO influence by rotating the shaded regions through a half-orbit.

series $P_{1}(t), P_{2}(t)$ as Cartesian planar coordinates $(x, y)$ and then convert to polar coordinates,

$$
\psi(t)=\frac{1}{2 \pi} \tan ^{-1}\left[\frac{y(t)}{x(t)}\right], \quad r(t)=\sqrt{x^{2}(t)+y^{2}(t)},
$$

where $(x, y)$ are identified either as $\left(P_{1}, P_{2}\right)$ or $\left(P_{2}, P_{1}\right)$ so as to make the phase angle $\psi(t)$ increase with time when QBO phase propagates downward. Apart from QBO stallings, most of the variance of $\bar{u}_{\mathrm{EQ}}(z, t)$ is expressed by the steady increase of $\psi$ with time, while the phase radius $r(t)$ varies more erratically and captures less of the variance. Note that $\psi$ has been normalized to take values in the range $[-0.5,0.5]$, so that a change over time of $\Delta \psi=1$ indicates that one QBO cycle has elapsed.

A composite group may be defined by selecting a range of $\psi$ values, denoted as $\psi^{G}$, that spans a $\psi$ range of width $\Delta \psi^{G}$. For example, $\psi^{G} \equiv[-0.25,0]$ denotes a group for which $-0.25 \leq \psi \leq 0$ (i.e., $\Delta \psi^{G}=0.25$ ). Winters are assigned to the group according to whether $\psi$ during a chosen month $M_{\psi}$ is within $\psi^{G}$. (For example, if $M_{\psi}=$ November then a winter belongs to the group if $\psi \in \psi^{G}$ during November of that winter.) These winters are composited to obtain the mean extratropical state associated with this group of QBO phase values (i.e., with $\left.\psi \in \psi^{G}\right)$. By defining a second group $\tilde{\psi}^{G}$ with opposite $\psi$ values (e.g., if $\psi^{G} \equiv[-0.25,0]$, then $\tilde{\psi}^{G} \equiv[0.25,0.5]$; see Fig. 5a), the difference of the mean $\psi^{G}$ and $\tilde{\psi}^{G}$ states then characterizes the extratropical anomalies associated with oppositely phased QBO states, analogous to the westerly/easterly differences shown in numerous studies of QBO-vortex coupling. By rotating $\psi^{G}$ and $\tilde{\psi}^{G}$ through 0.5 QBO cycles, we search for the contrast between opposing QBO phases that induces the greatest extratropical response. Figure 5 schematically illustrates this procedure. A given pair of opposing groups will be 
referred to as a $\psi^{G}-\tilde{\psi}^{G}$ pair. The specific criterion for optimizing the response is based on the $t$ statistic corresponding to the $\psi^{G}-\tilde{\psi}^{G}$ composite difference at a chosen extratropical location; this will be discussed in more detail in section $4 \mathrm{~b}$.

The value of $\Delta \psi^{G}$ is arbitrary; ideally we would like to make it as small as possible so as to diagnose the extratropical response to as many distinct $\bar{u}_{\mathrm{EQ}}$ states as possible, but we desire the groups to be large enough that statistically meaningful results are obtained. For ERA-40, we choose $\Delta \psi^{G}=0.25$ (as in Fig. 5a) so that each group contains roughly 10 members. For the 150-yr CMAM run, $\Delta \psi^{G}=0.15$ (as in Fig. $5 b$ ) yields groups with (roughly) between 15 and 30 members each. The fraction of $\psi$ space that is sampled by the opposing groups is $\Delta \psi^{G}+\Delta \tilde{\psi}^{G}=2 \Delta \psi^{G}$; hence, for ERA-40 (CMAM), any two opposing groups together comprise roughly half (one-third) of the available years.

For the purpose of defining ERA-40 composites, the tropical radiosonde winds are used to define $\psi$. ERA-40 $\bar{u}_{\mathrm{EQ}}(z)$ may be used instead with no substantial change to the results because of the strong correspondence in $\bar{u}_{\mathrm{EQ}}(z)$ between ERA-40 and the radiosonde data (Baldwin and Gray 2005), as noted in section 2. Radiosonde data were chosen so that $\mathbf{C}$ would be defined from the longest possible record (1956-2004 rather than 19582001). For CMAM composites, $\bar{u}_{\mathrm{EQ}}(z)$ averaged over $2^{\circ} \mathrm{N}-2^{\circ} \mathrm{S}$, over the same altitude range as the tropical radiosonde data, is used to define $\psi$.

\section{b. Northern Hemisphere winter}

By carrying out the optimization procedure described above, it is found that distinct QBO phases-that is, different $\psi^{G}-\tilde{\psi}^{G}$ pairs-are associated with the strongest $\mathrm{NH}$ early-winter and late-winter responses. For the $\mathrm{NH}$ analysis, we choose $M_{\psi}=$ November to define the $\psi^{G}$ and $\tilde{\psi}^{G}$ groups. Since QBO phase progresses slowly during NH winter (Wallace et al. 1993), choosing other $\mathrm{NH}$ winter months for $M_{\psi}$ produces generally similar results. It should be emphasized that for any given $\psi^{G}$ $\tilde{\psi}^{G}$ pair, a whole winter is assigned to a group (i.e., $\psi^{G}$ or $\tilde{\psi}^{G}$ ) based on the November value of $\psi$; hence, in the plots that follow, the progression of months shown (October through March) indicates the composited seasonal evolution of a particular group of winters, rather than some of the Octobers belonging to different winters than some of the Novembers and so on. Thus, for a given $\psi^{G}-\tilde{\psi}^{G}$ pair, the composite early-winter extratropical state is the antecedent of the late-winter state, conditional upon specified equatorial winds.

Figure 6 shows zonal cross sections depicting the seasonal evolution of the monthly average composite $\bar{u}$ differences, $\Delta \bar{u}$ associated with the $\psi^{G}-\tilde{\psi}^{G}$ pair that

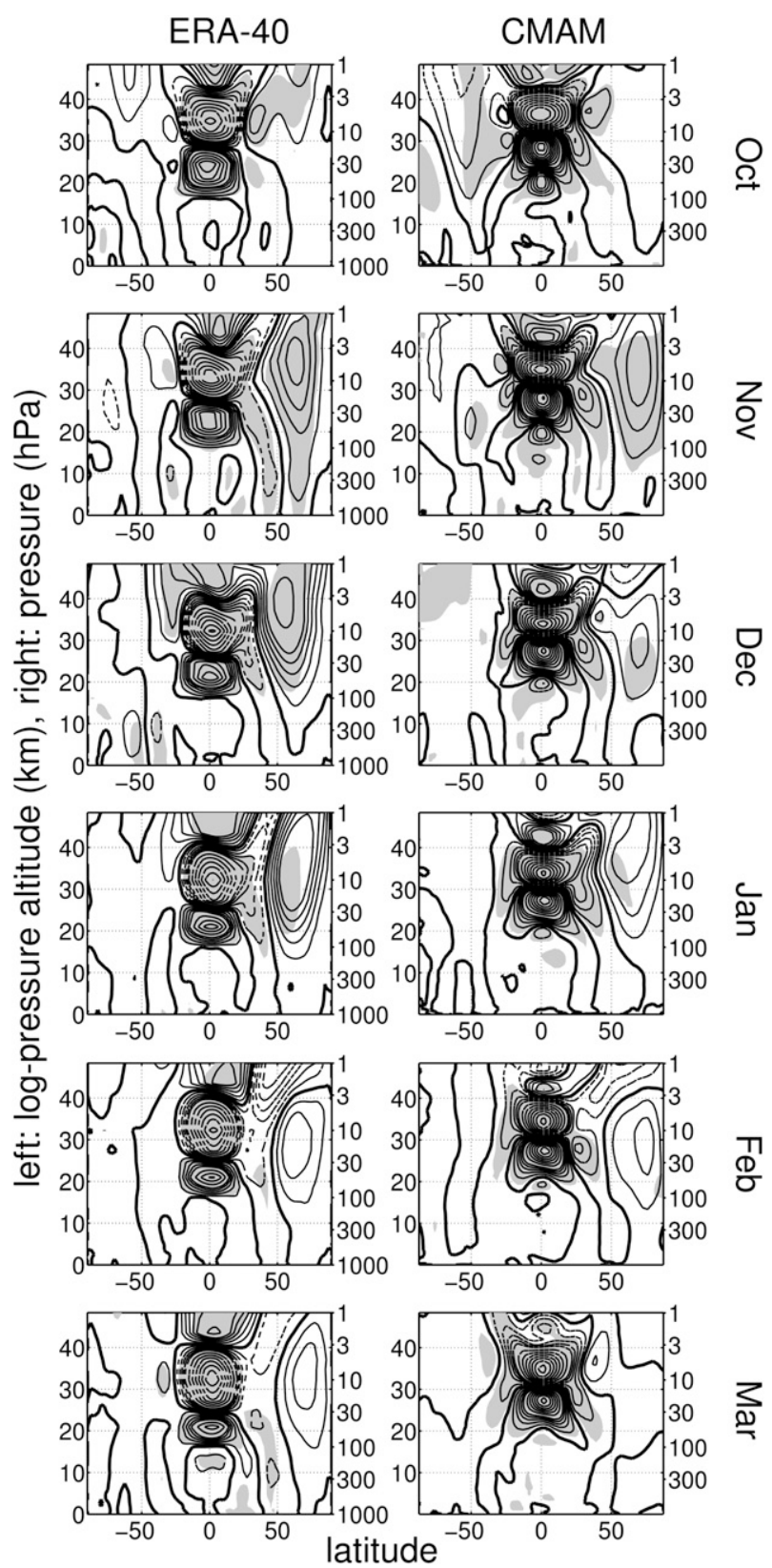

FIG. 6. Composite differences $\Delta \bar{u}$ for $\psi^{G}-\tilde{\psi}^{G}$ pairs that optimize the NH early-winter signal. Contour interval is $2 \mathrm{~m} \mathrm{~s}^{-1}$ for $|\Delta \bar{u}|<$ $10 \mathrm{~m} \mathrm{~s}^{-1}$ and $5 \mathrm{~m} \mathrm{~s}^{-1}$ for $|\Delta \bar{u}| \geq 10 \mathrm{~m} \mathrm{~s}^{-1}$. Shading indicates differences for which the $t$ statistic exceeds the $95 \%$ significance level by a two-sided test.

optimizes the early-winter response for each of ERA-40 and CMAM. Figure 6 indicates that the early-winter response, in both ERA-40 and CMAM, consists of an October midstratospheric anomaly (confined to the subtropics in CMAM) that by November has extended to high latitudes and become vertically deep, accompanied by an opposite-signed, vertically deep subtropical anomaly. The statistical significance of the early-winter signal 
is highest in November in both ERA-40 and CMAM. From December onward, Fig. 6 shows that the highlatitude anomaly persists, but its significance reduces as winter progresses. These features are common to both ERA-40 and CMAM. Additionally, the ERA-40 patterns are similar to the signature of the northern annular mode (NAM) in $\bar{u}$ shown in Fig. 2 of Baldwin and Dunkerton (1999). [Note that Baldwin and Dunkerton (1999) refer to this pattern as the Arctic Oscillation.] The vertical extent of the ERA-40 November response, which extends through the depth of the troposphere, may be consistent with the fact that NAM anomalies tend to propagate downward most rapidly in early winter (Baldwin and Dunkerton 1999). In CMAM, a tropospheric component of the high-latitude November response is not apparent. Nevertheless, since most previous AGCM studies have not reported any early-winter response at all, it is notable that a November stratospheric response occurs in CMAM. The amplitude $\Delta \bar{u}$ of the CMAM November response is weaker than that of the ERA-40 response, but its magnitude relative to the interannual variability of the vortex is similar, giving it a similar level of statistical significance.

Figure 7 is similar to Fig. 6 but depicts the seasonal evolution of $\Delta \bar{u}$ for those winters belonging to the $\psi^{G}-\tilde{\psi}^{G}$ pair that optimizes the late-winter response. In ERA-40 the response exhibits highest statistical significance in February, whereas for CMAM both January and February show high significance. It is notable that in both ERA-40 and CMAM, high significance for the latewinter response is achieved only when the early-winter (November) response is weak (i.e., its statistical significance is reduced). This suggests that QBO influence on the late-winter vortex is conditional upon the early-winter vortex behavior as well as on QBO phase itself. Winters for which the early-winter response is strong tend to have a weak late-winter response (Fig. 6), while winters with strong late-winter responses tend to exhibit weak early-winter responses (Fig. 7).

Details regarding the optimization procedure used to detect the early- and late-winter responses shown in Figs. 6 and 7 are given by Figs. 8 and 9. For each of the monthly averages indicated by the figure legends, the $t$ statistic corresponding to $\Delta \bar{u}$ at $50 \mathrm{hPa}(21 \mathrm{~km}), 60^{\circ} \mathrm{N}$ is plotted as a function of changing $\psi^{G}-\tilde{\psi}^{G}$ pairs. We use the form of $t$ that assumes equal population variances of the two samples being compared (i.e., of the $\psi^{G}$ and $\tilde{\psi}^{G}$ groups; von Storch and Zwiers 1999). The horizontal axes of Figs. 8 and 9 represent the incremental movement of $\psi^{G}-\tilde{\psi}^{G}$ pairs through 0.5 cycles of QBO phase (as depicted schematically in Fig. 5), using increments of 0.0125 , and the axis is labeled by the lowest $\psi$ value of a given $\psi^{G}$ group. Only $\psi$ values from -0.5 to 0 are
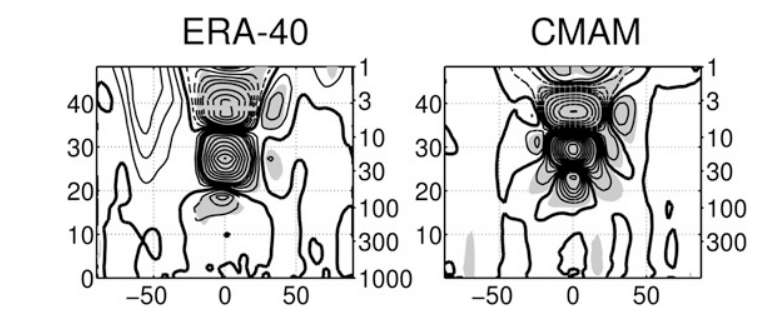

\section{웅}
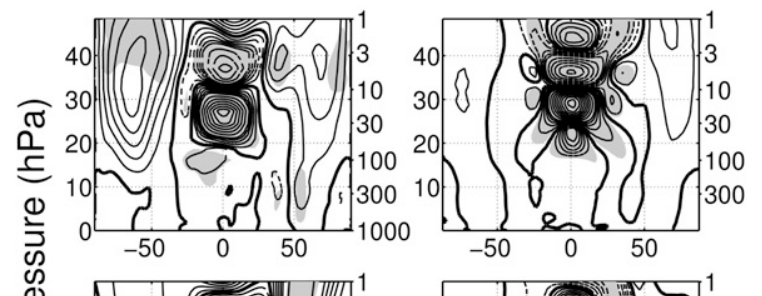

Z
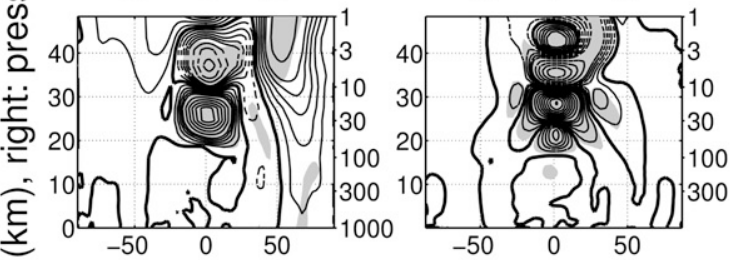

๑ุ
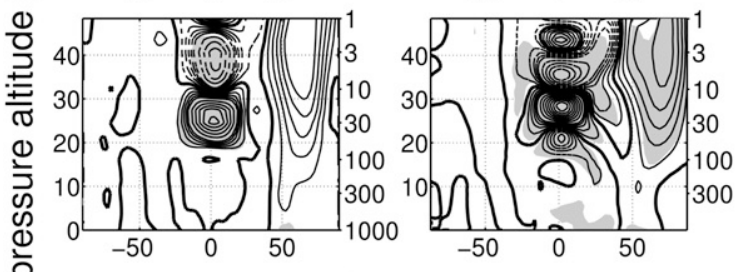

\section{$\stackrel{\complement}{丂}$}
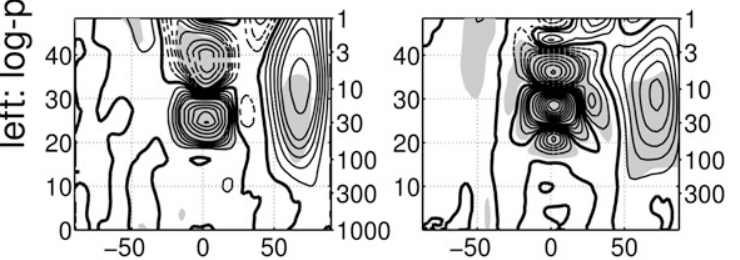

$\frac{\pi}{0}$

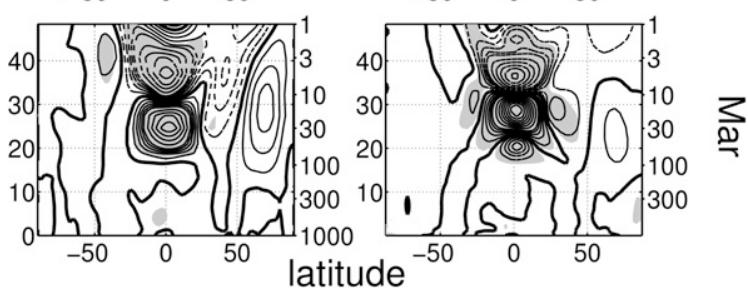

FIG. 7. As in Fig. 6, but for the NH late-winter signal.

shown on the horizontal axis since the curves for the other half-range of $\psi$ are identical but with opposite sign. The $\psi^{G}-\tilde{\psi}^{G}$ pairs chosen for presentation in Figs. 6 and 7 were selected based on their showing the largest $t$ values in Figs. 8 (for ERA-40) and 9 (for CMAM). The statistical significance of the $t$ values is assessed by assuming the degrees of freedom in the samples to be the number of years in the $\psi^{G}$ and $\tilde{\psi}^{G}$ groups, which are shown in the bottom panels of Figs. 8 and 9. It should be noted that the actual values of $\psi$ shown on the horizontal axes of Figs. 8 and 9 are arbitrary, in that $\psi$ is defined 

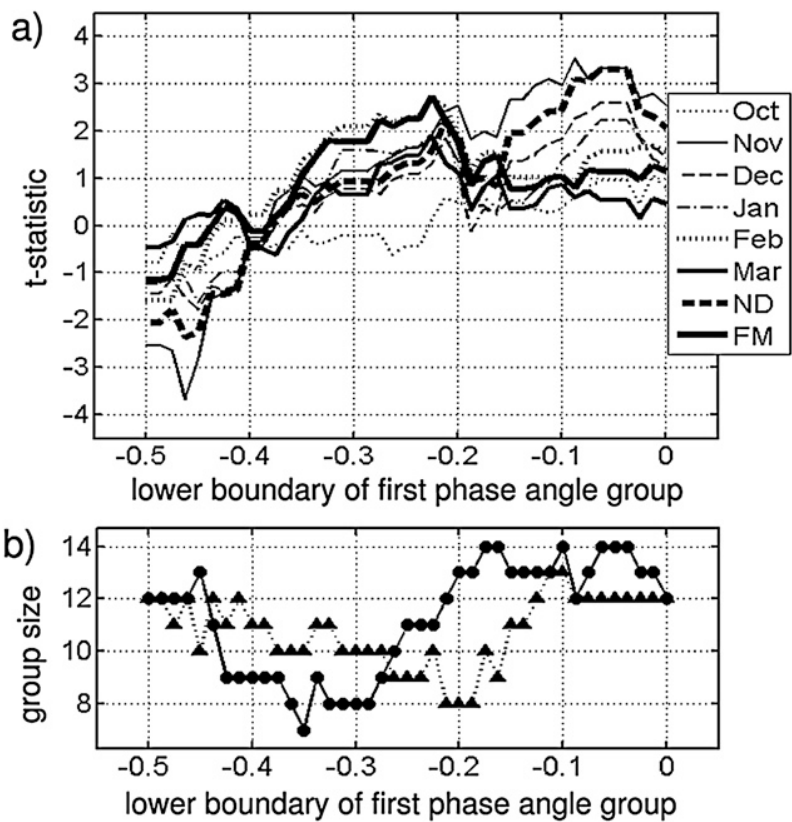

FIG. 8. (a) The $t$ statistic for ERA-40 monthly or bimonthly $\Delta \bar{u}$ at $60^{\circ} \mathrm{N}, 50 \mathrm{hPa}(21 \mathrm{~km})$ for varying $\psi^{G}-\tilde{\psi}^{G}$ pairs; ND and FM denote November-December and February-March averages, respectively. The horizontal axis is labeled using the lower boundary value of the $\psi^{G}$ group. (b) Sizes of the opposing groups for each $\psi^{G}-\tilde{\psi}^{G}$ pair shown in (a); circles (triangles) indicate the size of the $\psi^{G}\left(\tilde{\psi}^{G}\right)$ group.

only to within an arbitrary additive constant; thus, it is the differences in $\psi$ between the locations of peak $t$ values that are meaningful, and it is these differences that should be compared between ERA-40 and CMAM.

Figures 8 and 9 illustrate the point already noted that for both ERA-40 and CMAM, the $\psi^{G}-\tilde{\psi}^{G}$ pairs exhibiting a strong early-winter response show a weak late-winter response, and vice versa. The statistical significance of the early-winter response in ERA-40 is higher than that of the late-winter response; for the single-month means, this is also true in CMAM (November has higher significance than January or February). Figure 8 shows that the early-winter and late-winter peaks in ERA-40 are separated by $\sim 0.2$ of a QBO cycle, while Fig. 9 shows that the corresponding CMAM separation is $\sim 0.1$ of a QBO cycle. For both ERA- 40 and CMAM, the late-winter response is strongest when QBO phase in November is at an earlier stage of the QBO cycle than is the case when the early-winter response is strongest. However, the different positions of the early- and latewinter peaks in Figs. 8 and 9 are not simply a consequence of the time difference between November and February within a QBO cycle. This is seen by comparing $\Delta \bar{u}_{\mathrm{EO}}$ in the November panels of Fig. 6 with $\Delta \bar{u}_{\mathrm{EO}}$ in the February panels of Fig. 7. For ERA-40, the QBO phase
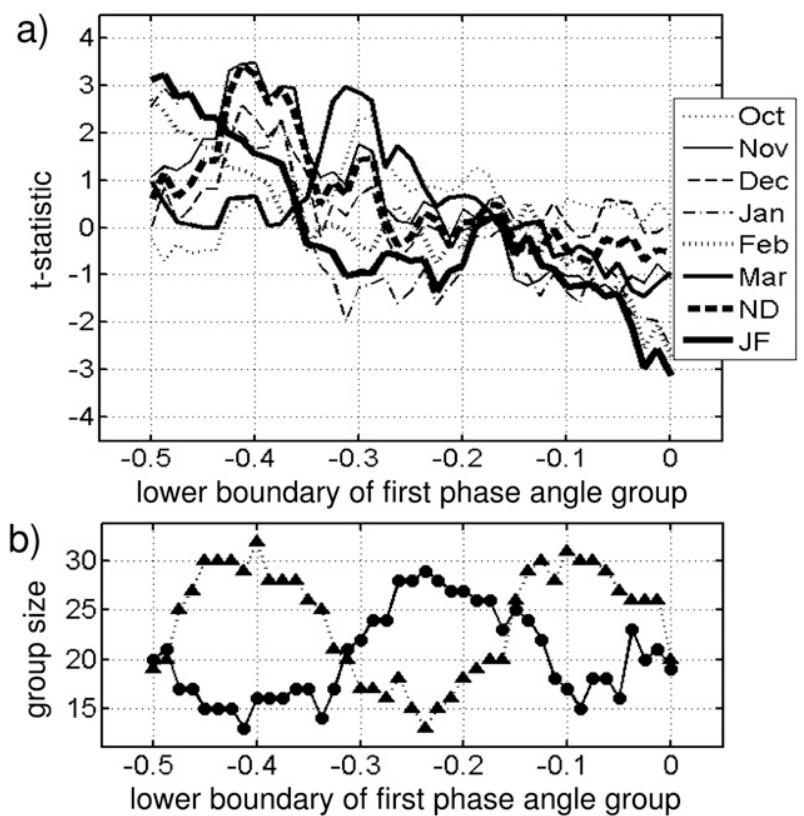

FIG. 9. As in Fig. 8, but for CMAM; JF denotes the January-February average.

occurring concurrently with the most highly significant vortex response is different in the two cases; for CMAM there is also a difference, albeit a smaller one. This point will be returned to in section 5 .

The ERA-40 results of Fig. 8 are consistent with Fig. 4 of Anstey and Shepherd (2008; hereafter AS08), which used a different definition of QBO phase based on the timing of QBO phase initiations at a given vertical level. [The left-to-right order of peaks in Fig. 8 is opposite to that of AS08's Fig. 4. This is because the initiation of a given QBO phase at a longer (shorter) lead time with respect to $\mathrm{NH}$ winter implies that $\psi$ will be more (less) advanced by the time winter arrives.] Applying the AS08 method to CMAM also yields results that are consistent with the EOF-based method employed here (not shown).

\section{c. Southern Hemisphere winter}

We now apply the same analysis as described in section 4 a to $\mathrm{SH}$ winter. As with the $\mathrm{NH}$ case, distinct $\mathrm{QBO}$ phases are found to optimize the early- and late-winter vortex responses to $\mathrm{QBO}$ phase. We choose $M_{\psi}=$ August for the SH. The SH results are more sensitive to the choice of $M_{\psi}$ than the NH results in that choosing a midwinter month (e.g., August) tends to maximize the late-winter (November) vortex response, whereas an early winter month (e.g., May) tends to maximize the early-winter response. The greater sensitivity of the $\mathrm{SH}$ results to the choice of $M_{\psi}$ is most likely due to the fact that $\psi$ progresses more rapidly during $\mathrm{SH}$ winter, and 


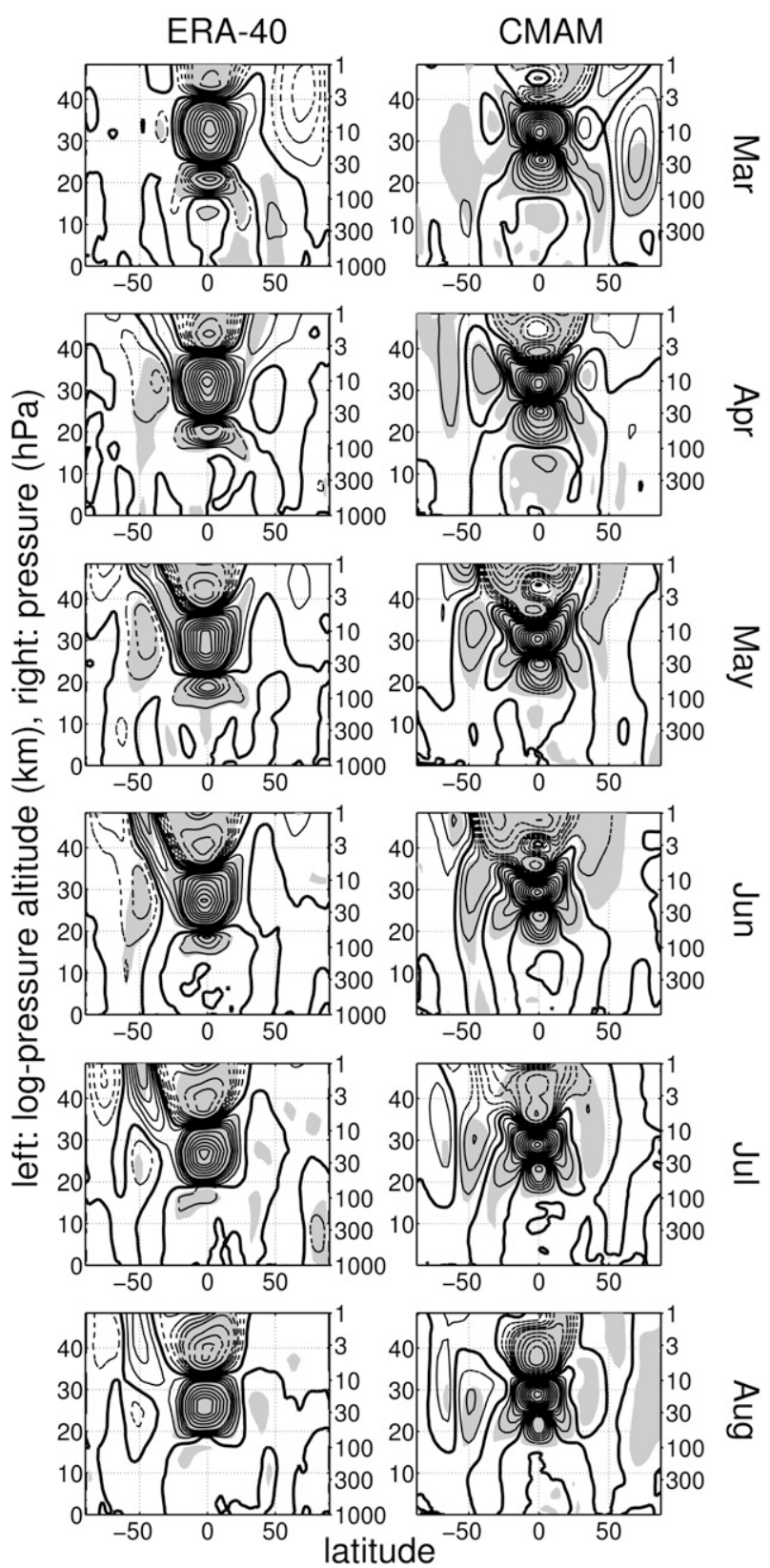

FIG. 10. As in Fig. 6, but for the SH early-winter signal.
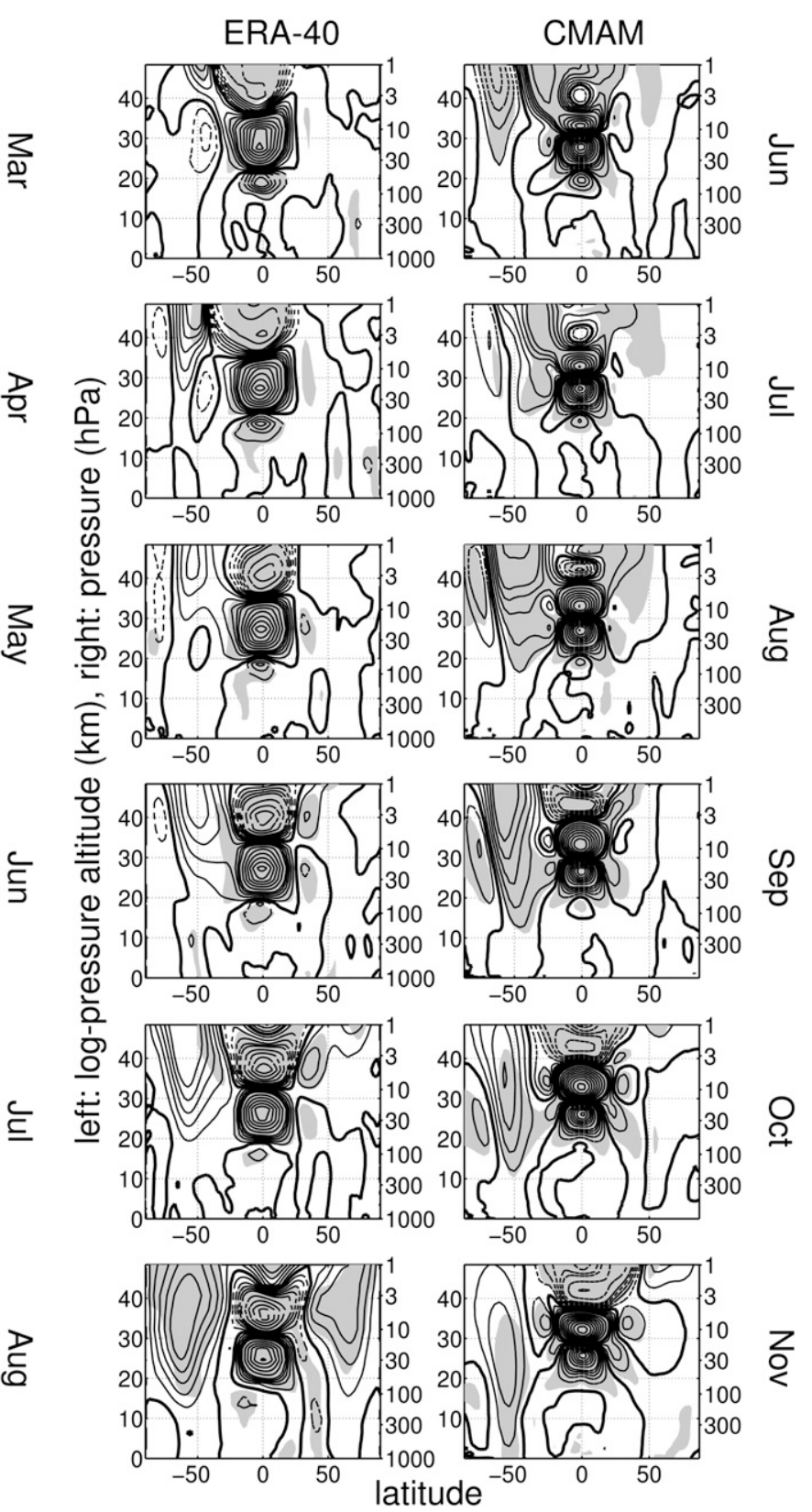

FIG. 11. As in Fig. 6, but for the SH late-winter signal.

significance during May and June, with the ERA-40 and CMAM responses having similar amplitudes. For brevity the final months of SH winter (September-November) are excluded from Fig. 10, but they display a weak vortex response, with low statistical significance, in both ERA-40 and CMAM.

Figure 11 is similar to Fig. 10, but for the $\psi^{G}-\tilde{\psi}^{G}$ pair that optimizes the SH late-winter response. The latewinter response in ERA-40 is strongest in November, consisting of a modulation of the timing of the final vortex breakdown (Baldwin and Dunkerton 1998). The 

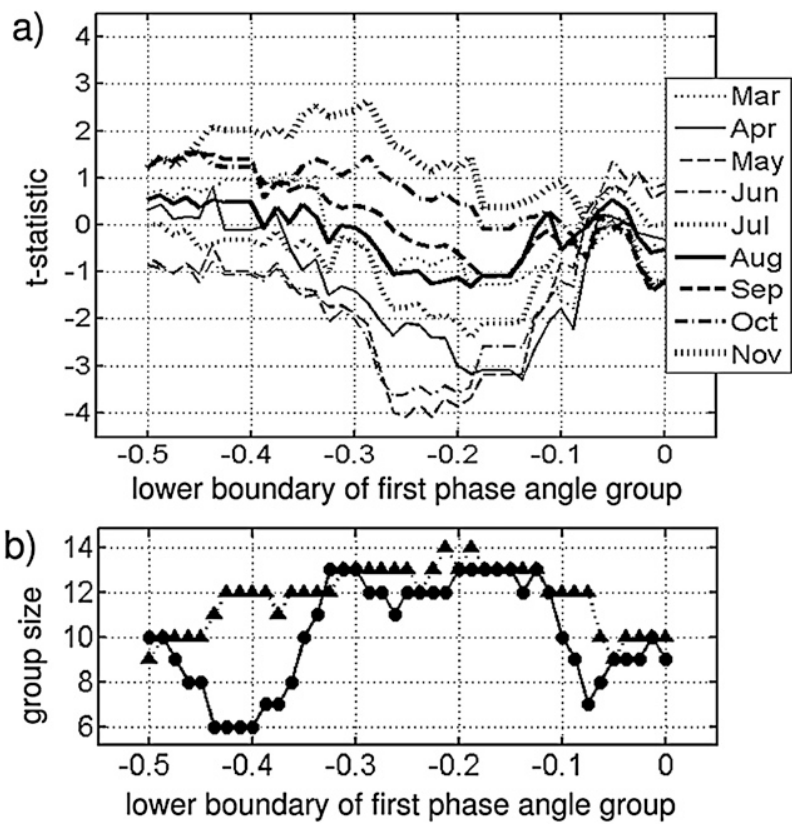

FIG. 12. As in Fig. 8, but for the SH. (a) The $t$ statistic for ERA-40 $\Delta \tilde{u}$ at $30 \mathrm{hPa}(25 \mathrm{~km})$, averaged over $50^{\circ}-60^{\circ} \mathrm{S}$ [weighted by $\cos (\phi)]$, for varying $\psi^{G}-\tilde{\psi}^{G}$ pairs.

CMAM late-winter response displays a similar pattern of development as the ERA-40 response but also shows high statistical significance in the months leading up to November. Again for brevity's sake, the earlier months of SH winter are excluded from Fig. 11, but they indicate a weak early-winter response.

Figures 12 and 13 are the SH equivalents of Figs. 8 and 9. The $t$ statistic shown in Figs. 12 and 13 corresponds to $\Delta \bar{u}$ at $30 \mathrm{hPa}(25 \mathrm{~km})$, averaged over $50^{\circ}-60^{\circ} \mathrm{S}$ [weighted by $\cos (\phi)$ ]. This different choice of grid point reflects the differences in the spatial structure of the response $\Delta \bar{u}(\phi, z)$ in the $\mathrm{NH}$ and $\mathrm{SH}$ winters. The latitudinal range $50^{\circ}-60^{\circ} \mathrm{S}$ is chosen to capture the poleward edge of the early-winter midlatitude response while retaining a strong signal for the late-winter (November) response. Note that the displayed polarity of the response patterns $\Delta \bar{u}$ in Figs. 10 and 11 was chosen to show the most significant extratropical anomaly having the same sign for both ERA-40 and CMAM.

As was the case for the NH, Figs. 12 and 13 show that a strong early-winter response tends to accompany a weak late-winter response, and vice versa. For CMAM, Fig. 13 shows a wide separation of $\sim 0.2$ cycles between the May-July peaks and the middle of the broad SeptemberNovember peaks. For ERA-40, Fig. 12 shows that the separation between the centers of the broad May-June peaks and the November peak is smaller, $\sim 0.1$ cycles. CMAM also exhibits a strong August response, not seen in ERA-40, the peak of which lies midway between the
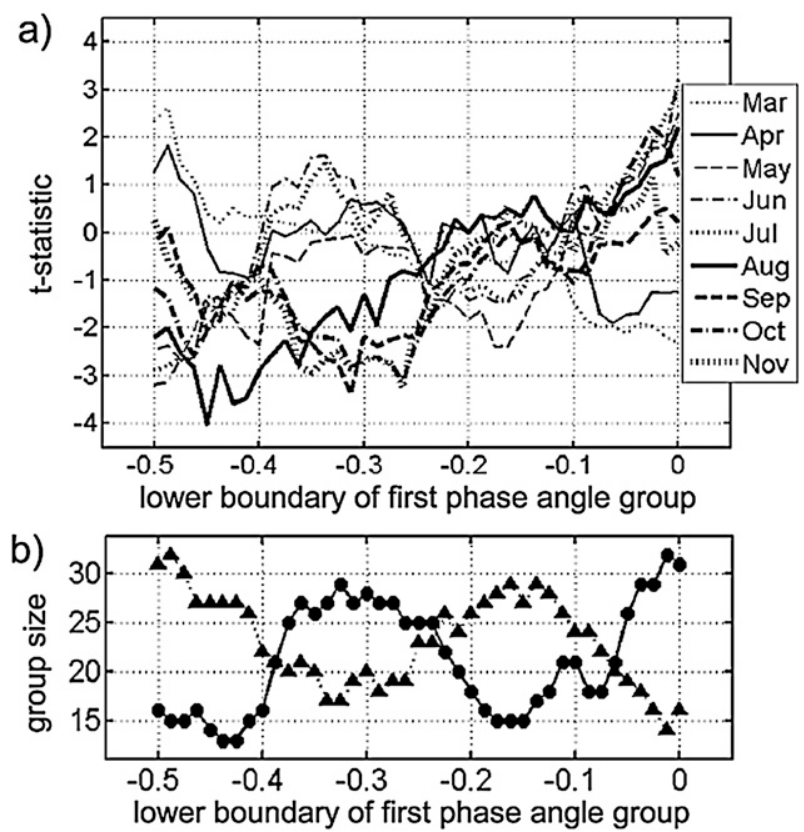

FIG. 13. As in Fig. 12, but for CMAM.

May-July and September-October peaks in Fig. 13. As with the $\mathrm{NH}$, application of the AS08 method to the $\mathrm{SH}$ for both ERA-40 and CMAM yields results consistent with the EOF-based method used here (not shown).

\section{Discussion}

We denote the QBO phase that optimally excites a polar vortex response as $\psi^{*}$. The results of section 4 show that $\psi^{*}$ differs between the two hemispheres' winters, and that $\psi^{*}$ in early winter, $\psi_{\mathrm{EW}}^{*}$, is not the same as $\psi^{*}$ in late winter, $\psi_{\mathrm{LW}}^{*}$. A clearer illustration of the different $\bar{u}_{\mathrm{EQ}}(z)$ cases corresponding to $\mathrm{NH} \psi_{\mathrm{EW}}^{*}$ and $\psi_{\mathrm{LW}}^{*}$ is given by Figs. 14 and 15 (for ERA-40 and CMAM, respectively), which show the mean wind profiles $\bar{u}_{\mathrm{EQ}}(z)$ for the relevant $\psi^{G}$ and $\tilde{\psi}^{G}$ groups, the difference of means in the $\Delta \bar{u}_{\mathrm{EQ}} \mathrm{s}$, and the profiles for the individual years in each group. The distinction between $\bar{u}_{\mathrm{EQ}}(z)$ profiles corresponding to the $\psi_{\mathrm{EW}}^{*}$ and $\psi_{\mathrm{LW}}^{*}$ cases is clearer for ERA-40 than for CMAM, consistent with the smaller phase difference $\psi_{\mathrm{EW}}^{*}-\psi_{\mathrm{LW}}^{*}$ seen in Fig. 9 (CMAM) than in Fig. 8 (ERA-40) in the NH.

Seasonal variation in the relationship between $\mathrm{QBO}$ phase and polar vortex state was examined in ERA-40 data by Hitchman and Huesmann (2009), who noted that different QBO shear indices appeared to excite a polar vortex response in different seasons (i.e., that $\psi^{*}$ was not the same in all seasons). Seasonal variation of the observed QBO-vortex relationship is especially pronounced in the $\mathrm{SH}$, where the midwinter vortex appears not to be 

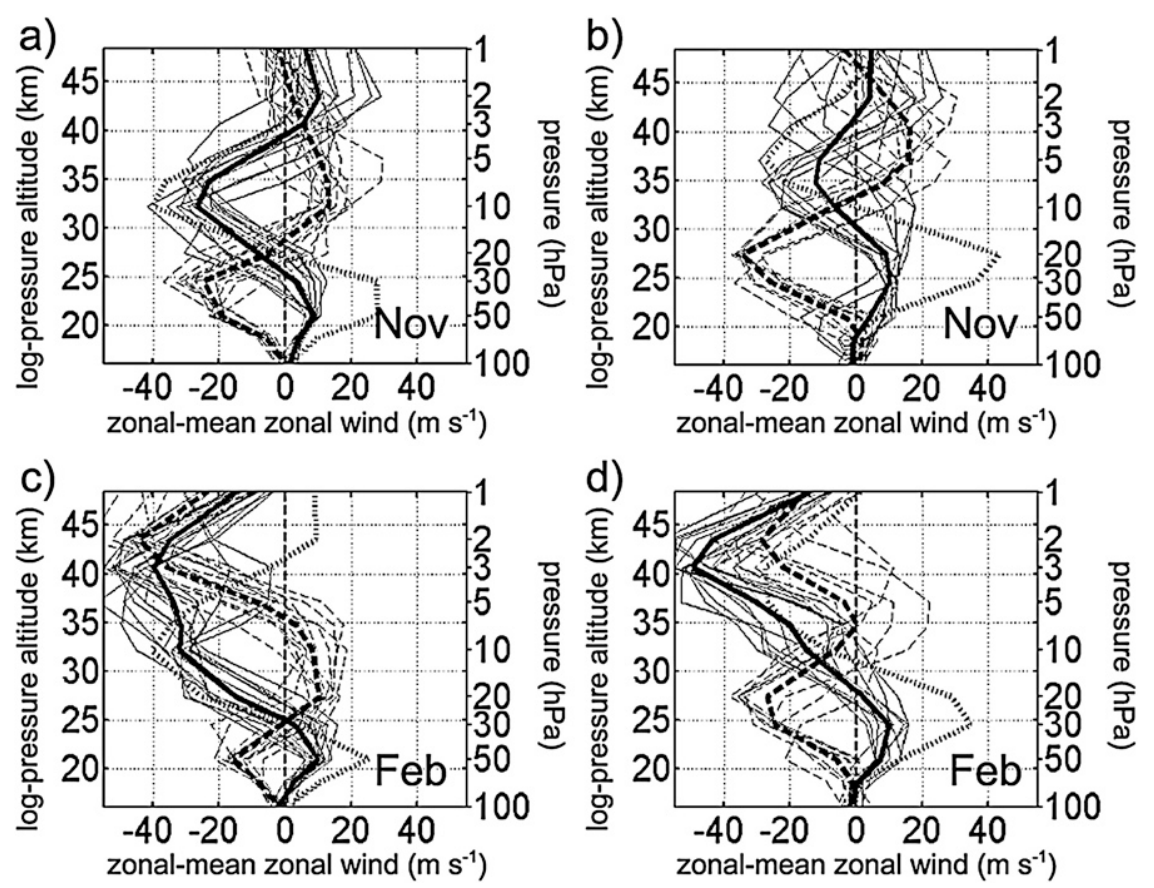

FIG. 14. ERA-40 equatorial $\bar{u}(z)$ profiles for the $\psi^{G}-\tilde{\psi}^{G}$ grouping that optimizes (a),(c) the $\mathrm{NH}$ early-winter vortex response and (b),(d) the NH late-winter vortex response. For each of these groupings, $\bar{u}(z)$ is shown during (a),(b) November and (c),(d) February. Thin solid (dashed) lines are individual years' profiles belonging to the $\psi^{G}\left(\tilde{\psi}^{G}\right)$ group. The corresponding thick lines indicate the mean profiles for each group, and the thick dashed line shows the difference of the mean profiles.

influenced by QBO phase at all (Baldwin and Dunkerton 1998). The seasonal distinction is murkier in the NH, although it has long been known that the most statistically significant correlation between QBO phase and the $\mathrm{NH}$ vortex occurs in November (Dunkerton and Baldwin 1991; O'Sullivan and Dunkerton 1994). Modeling studies have mainly examined the QBO-vortex relationship in $\mathrm{NH}$ midwinter, focusing not on the early-winter signal but rather on the relationship between QBO phase and SSW frequency. Apart from the results presented here, the only AGCM study to report a November NH QBOvortex coupling is that of Pascoe et al. (2006). Hence, the seasonal variation of the relationship between QBO phase and the polar vortex has been little addressed by modeling studies, and only recently has the observed record become long enough that it may be diagnosed statistically in reanalysis data.

Why does $\psi^{*}$ vary seasonally-that is, why is $\psi_{\mathrm{EW}}^{*} \neq$ $\psi_{\mathrm{LW}}^{*}$ ? It may be the case that the seasonal cycle of polar vortex strength and shape underlies the seasonal dependence of $\psi^{*}$ that we have diagnosed, in that vortex sensitivity to $\psi^{*}$ depends on the (seasonally varying) vortex state. This hypothesis could be tested with mechanistic studies using imposed $\Delta \bar{u}_{\mathrm{EQ}}(z)$ perturbations of the forms shown in Fig. 14, as well as the equivalent $\mathrm{SH}$
$\bar{u}_{\mathrm{EO}}(z)$ profiles, with radiative conditions and planetary wave forcing appropriate to the season and hemisphere.

However, existing mechanistic studies have shown that the strongest influence of a given $\bar{u}_{\mathrm{EQ}}$ on the high-latitude circulation occurs when the polar vortex is of intermediate strength rather than when it is excessively weak (e.g., during SSWs) or excessively strong (see section 1). Given this sensitivity, it is plausible that a strong QBO influence in early winter tends to bias the vortex toward a more extreme state, thereby making the vortex less susceptible to QBO influence later in the winter. Conversely, the absence of strong QBO influence in early winter may increase the likelihood of a late-winter QBO influence becoming manifest. We refer to this notion as the "interference hypothesis," implying that the earlywinter vortex response may interfere with the late-winter response. The observed persistence time scales for vortex anomalies in the $\mathrm{NH}$ and $\mathrm{SH}$ (Baldwin et al. 2003) and upward wave flux anomalies in the $\mathrm{NH}$ (Karpetchko and Nikulin 2004) are consistent with such behavior.

Support for the interference hypothesis is suggested by the empirical distribution functions shown in Fig. 16, which are estimates of the true cumulative probability distributions, for $\bar{u}$ at $50 \mathrm{hPa}(21 \mathrm{~km}), 60^{\circ} \mathrm{N}$ for ERA-40 and CMAM. The months shown are the 2-month averages 

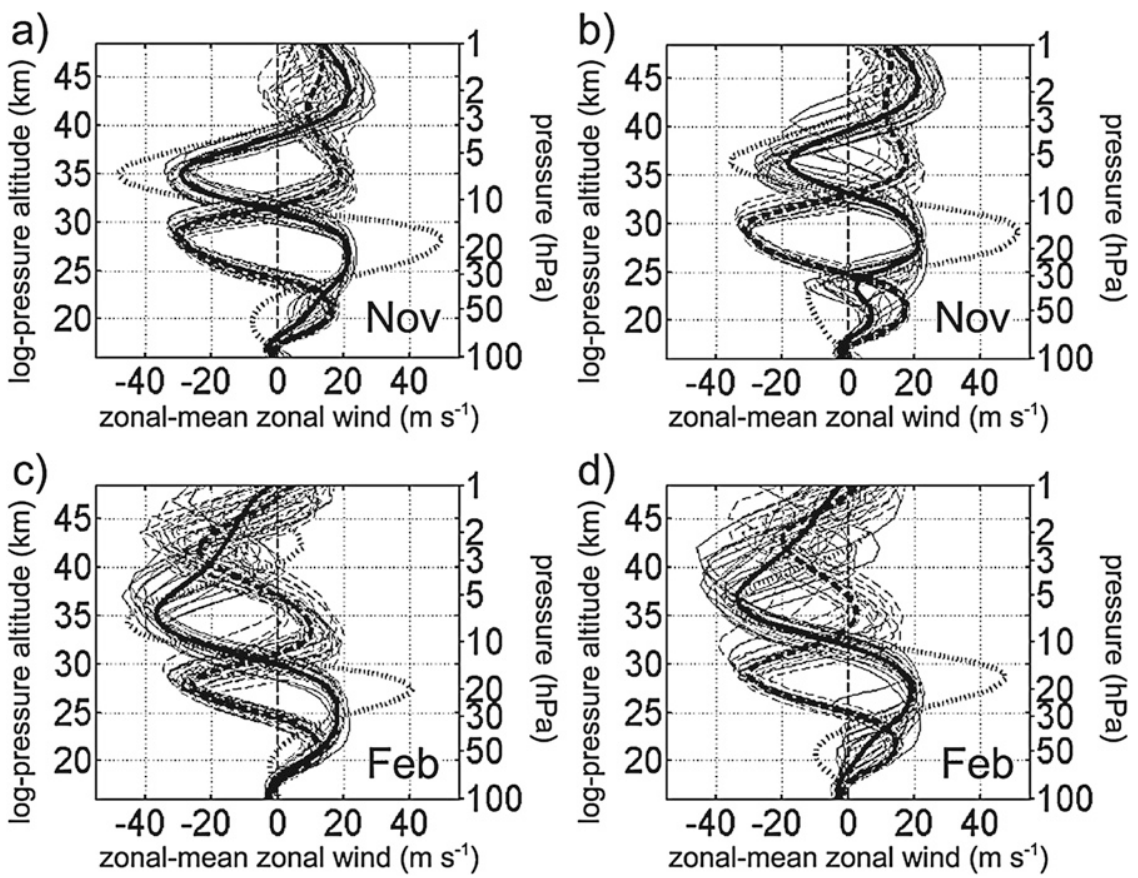

FIG. 15. As in Fig. 14, but for CMAM $\bar{u}$ averaged over $2^{\circ} \mathrm{N}-2^{\circ} \mathrm{S}$.

that give the strongest early- and late-winter responses, as indicated by Figs. 8 and 9. For the early-winter $\psi^{G}-\tilde{\psi}^{G}$ pairs, a large difference of means, accompanied also by shifts in the extreme values of the distributions, characterizes the early winter months (November-December), while the subsequent late-winter months (February-March for ERA-40 and January-February for CMAM) show a small difference of means, with lesser shifts in the extreme values. Conversely, the late-winter $\psi^{G}-\tilde{\psi}^{G}$ pairs show the opposite: with a smaller early-winter difference of means and lesser shifts in the extreme values, the late-winter differences and shifts in extreme values are increased.

We have thus far discussed the seasonal variation of $\psi^{*}$ without addressing why $\psi_{\mathrm{EW}}^{*}$ and $\psi_{\mathrm{LW}}^{*}$ take the particular values they do. That is, which QBO altitudes are most causal for the QBO-vortex coupling? Because our study is diagnostic we can draw no definitive conclusion about causality, but the following features are notable. In the $\mathrm{NH}$, the ERA-40 November vortex is strongest when a tropical easterly layer exists in the $z \approx 30-40-\mathrm{km}$ region, as shown by comparison of Figs. 14a and 14b. Concurrently a layer of westerlies is found in the $z \approx 20-30 \mathrm{~km}$ region, but in November this does not result in a robust shift of the zero-wind line $(\bar{u}=0)$ into the SH at these altitudes. Rather, modulation of the hemisphere of the zero-wind line prior to December occurs mainly at altitudes above $z \approx 30 \mathrm{~km}(\approx 10 \mathrm{hPa})$, as illustrated by the composited evolution of the ERA-40 early-winter $\psi^{G}$ and $\tilde{\psi}^{G}$ groups shown in Fig. 17. This suggests that causality for the $\mathrm{NH}$ early-winter QBO influence may originate in the $z \approx 30-40$ layer. Such a conclusion would be consistent with the results of Gray et al. (2004), who found that imposing easterlies in the $z \approx 30-40$ region in their mechanistic model led to a robust early-winter strengthening of the vortex (see their Fig. 4d, at 70-100 days). Although the conventional understanding of the QBO-vortex coupling would suggest that tropical easterlies should lead to a weakened rather than a strengthened vortex, Polvani et al. (1995) showed that planetary wave breaking in the presence of radiative relaxation in their shallow-water model induced strengthening of the zonal-mean polar vortex (see their Fig. 9a). Of course, it is possible that the weak subtropical winds in the $z \approx$ 20-30-km layer seen in Fig. 17 do not form an effective barrier to planetary wave propagation, and that the waves do feel the effects of the QBO westerlies at these altitudes. However, using a single-layer mechanistic model, Chen (1996) found that weak subtropical winds served to form a barrier that effectively isolated the high-latitude circulation from tropical influence. Comparison of Figs. 15a and 15b shows that in CMAM a stronger November $\mathrm{NH}$ vortex is also accompanied by a difference of $\bar{u}_{\mathrm{EQ}}(z)$ profiles in the midstratosphere, although the pattern is shifted slightly upward in comparison to ERA-40.

In late winter, QBO phase is associated with a modulation of the hemisphere of the zero-wind line in both the lower $(z \approx 20-30)$ and middle $(z \approx 30-40)$ stratospheric layers. Hence, it is less clear which of these altitude ranges 
a) early winter
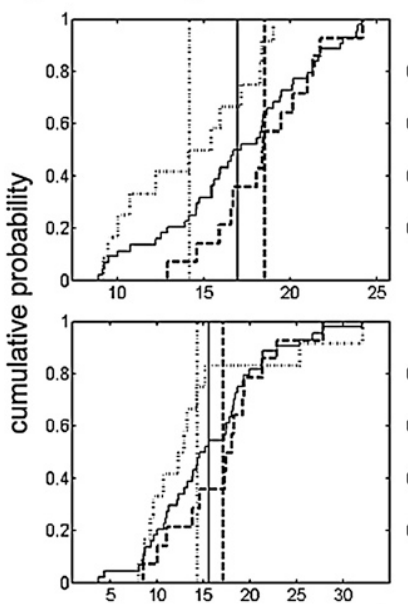

zonal-mean zonal wind at $60^{\circ} \mathrm{N} 50 \mathrm{hPa}\left(\mathrm{m} \mathrm{s}^{-1}\right)$

b)
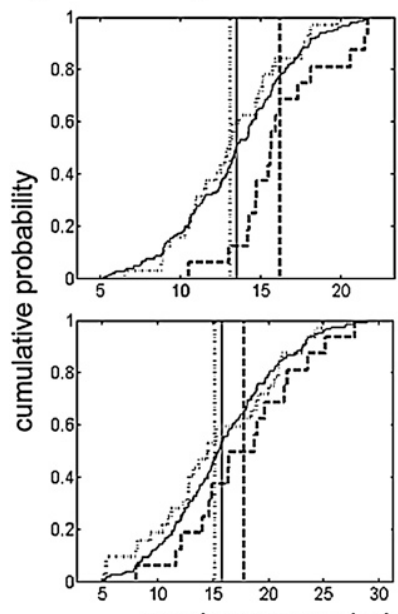

zonal-mean zonal wind at $60^{\circ} \mathrm{N} 50 \mathrm{hPa}\left(\mathrm{m} \mathrm{s}^{-1}\right)$

FIG. 16. Empirical distribution functions for $\bar{u}$ at $50 \mathrm{hPa}(21 \mathrm{~km})$, $60^{\circ} \mathrm{N}$ in (a) ERA-40 and (b) CMAM, for the monthly means indicated on the right. (left) Years belonging to the $\psi^{G}-\tilde{\psi}^{G}$ pair that optimizes the $\mathrm{NH}$ early-winter $t$ statistic (right) years belonging to the $\psi^{G}-\tilde{\psi}^{G}$ pair that optimizes the NH late-winter $t$ statistic (as defined by Figs. 8 and 9$) ; \psi^{G}\left(\tilde{\psi}^{G}\right)$ years are the dashed (dotted) lines, and the distribution of all years in the record is shown as the thinner solid line. The corresponding vertical lines indicate the means of each distribution.

is more causally significant for QBO influence on the polar vortex. As suggested above, the lagged influence of early-winter QBO influence, when it occurs, may complicate efforts to infer the causality of the late-winter QBO influence; hence, our results suggest that realistic simulation of late-winter QBO influence requires realistic simulation of early-winter QBO influence.

The interference hypothesis may explain why Figs. $14 \mathrm{c}, \mathrm{d}$ and $15 \mathrm{c}, \mathrm{d}$ are associated with weak and strong latewinter vortex responses. In CMAM especially, it is unclear why such a small $\psi_{\mathrm{EW}}^{*}-\psi_{\mathrm{LW}}^{*}$ difference should be
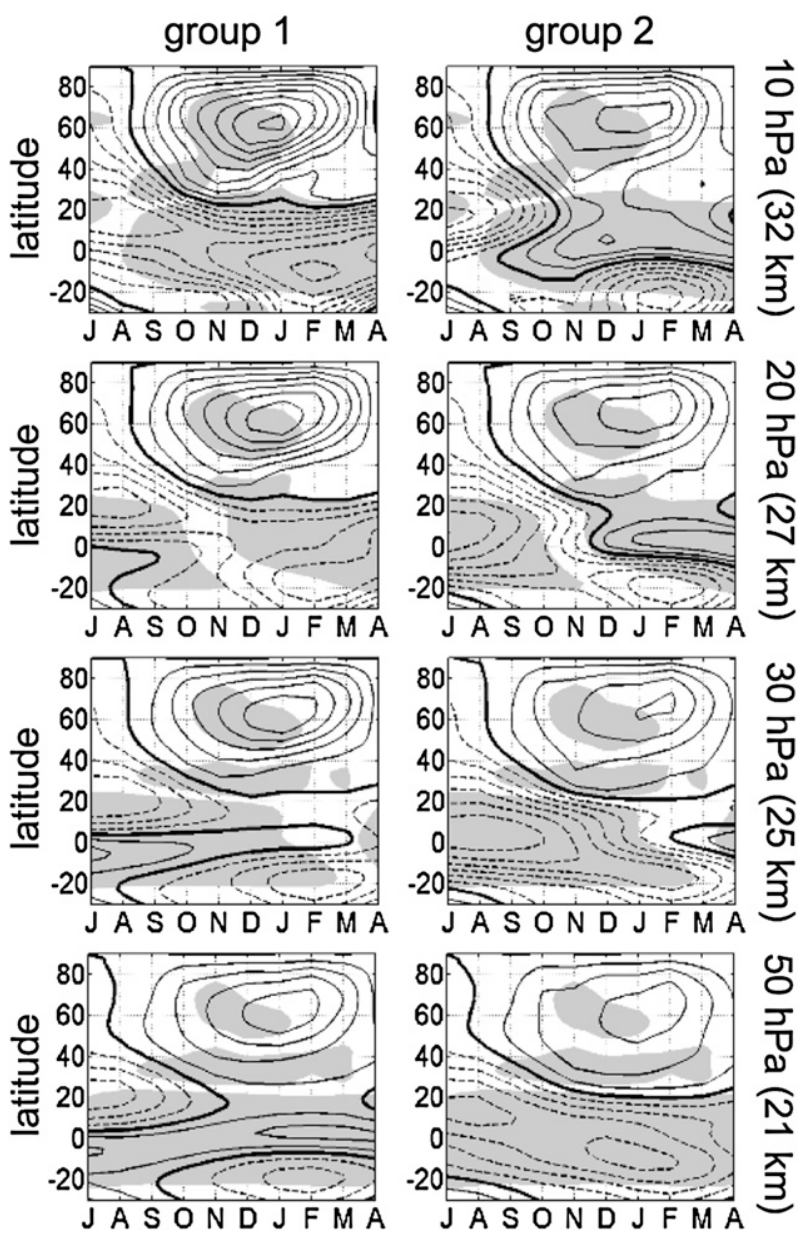

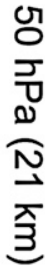

FIG. 17. Composite ERA-40 $\bar{u}$ evolution for the (left) $\psi^{G}$ and (right) $\tilde{\psi}^{G}$ groups that optimize the early-winter NH signal, at (top to bottom) the 10- $(32 \mathrm{~km}), 20-(27 \mathrm{~km}), 30-(25 \mathrm{~km})$, and $50-\mathrm{hPa}$ $(21 \mathrm{~km})$ vertical levels. The 5- $(37 \mathrm{~km})$ and $7-\mathrm{hPa}(35 \mathrm{~km})$ levels are not shown but look very similar to the $10-\mathrm{hPa}$ evolution. Contour interval is $5 \mathrm{~m} \mathrm{~s}^{-1}$; shading is as in Fig. 6.

associated with very different strengths of the vortex response. However, if the appearance of the late-winter response is modulated by the early-winter response, then it may not be the distinction between the $\bar{u}_{\mathrm{EQ}}$ profiles themselves that matters so much as the condition of the vortex leading up to February. That is, it may be that in the absence of interference from the early-winter response, either of the pairs of mean $\bar{u}_{\mathrm{EQ}}(z)$ profiles in Figs. $14 \mathrm{c}, \mathrm{d}$ and $15 \mathrm{c}, \mathrm{d}$ would generate a similar late-winter response.

The interference hypothesis may also shed light on the differences in the SH late-winter vortex response between ERA-40 and CMAM. Figure 10 showed that there is some similarity between the $\Delta \bar{u}_{\mathrm{EQ}}$ patterns that correspond to the SH early-winter response in ERA-40 and CMAM: both consist of westerlies overlying easterlies, 
albeit with the CMAM pattern shifted slightly upward in comparison to ERA-40 (as was the case for the NH early-winter $\Delta \bar{u}_{\mathrm{EO}}$ patterns). In contrast, Fig. 11 shows that the $\Delta \bar{u}_{\mathrm{EQ}}$ patterns corresponding to the late-winter response are quite different in ERA-40 and CMAM. This difference may be due to a combination of earlylate winter interference, given the longer time scale for intraseasonal vortex memory in the $\mathrm{SH}$, combined with the different rates of QBO phase progression in ERA-40 and CMAM. Figure 10 shows that CMAM $\Delta \bar{u}_{\mathrm{EO}}$ in August for the early-winter $\psi^{G}-\tilde{\psi}^{G}$ pair resembles ERA-40 $\Delta \bar{u}_{\mathrm{EQ}}$ in August for the late-winter $\psi^{G}-\tilde{\psi}^{G}$ pair, shown in Fig. 11. Hence, if CMAM reaches this QBO state in August, it does so during winters in which a strong early-winter response is likely to have already occurred. Conversely, Fig. 10 shows that ERA-40 $\Delta \bar{u}_{\mathrm{EQ}}$ in August for the early-winter $\psi^{G}-\tilde{\psi}^{G}$ pair resembles CMAM $\Delta \bar{u}_{\mathrm{EQ}}$ in August for the late-winter $\psi^{G}-\tilde{\psi}^{G}$ pair, shown in Fig. 11 (with opposite polarity). Hence if ERA-40 reaches this QBO state in August, which is the state that in CMAM is associated with a strong late-winter response, it does so during winters in which a strong early-winter response is likely to have already occurred. Thus, it is plausible that the interference hypothesis explains the large discrepancy between ERA-40 and CMAM in the $\Delta \bar{u}_{\mathrm{EQ}}$ patterns associated with the SH late-winter vortex response.

Irrespective of the reason why $\psi_{\mathrm{EW}}^{*} \neq \psi_{\mathrm{LW}}^{*}$, the seasonal variation of $\psi^{*}$ may have implications for the decadal variability of the strength of QBO-vortex correlations. Irregular decadal variability in the seasonality of QBO phase transitions, evident in Fig. 3, implies irregular decadal variability in the phase alignment of the QBO with respect to the annual cycle. That is, the tendency of QBO phase initiations to sometimes cluster seasonally on a decadal time scale implies that certain phase alignments of the QBO with respect to the annual cycle are more common in some periods than in others. If such phase alignments favor strong QBO influence on the polar vortex, then QBO-vortex correlations will be strong during those periods. Hence the diagnosed seasonal variation of $\psi^{*}$, in conjunction with the irregular decadal clustering of QBO phase transitions shown in Fig. 3, may lead to decadal variations in the susceptibility of the vortex to QBO influence.

In our model, which uses climatological SSTs and has no externally imposed sources of interannual variability (11-yr solar cycle, changing greenhouse gases, etc.), the decadal clustering of QBO phase transitions evident in Fig. 3 is due to internal atmospheric variability. We may hypothesize that this is also the case in the real atmosphere. The common features shared by our CMAM and ERA-40 results (section 4) lend support to this view.
Hence, our results suggest that the existence of externally imposed interannual forcings is not a necessary condition for decadal time-scale fluctuations in the strength of the QBO-vortex coupling to occur. Additional modeling work-ideally, with an AGCM that exhibits a more realistic spontaneous QBO than the one considered herewould provide valuable further tests of this conjecture.

\section{Conclusions}

Consistent with previous studies (Baldwin and Dunkerton 1998; Hitchman and Huesmann 2009), our results show that the optimal QBO phase for vortex influence differs between the $\mathrm{NH}$ and the $\mathrm{SH}$ and that the qualitative nature of QBO influence also differs in the two cases: the $\mathrm{NH}$ is characterized by modulation of vortex strength at high latitudes in both early winter and late winter, whereas the $\mathrm{SH}$ response occurs at midlatitudes in early winter (on the equatorward side of the vortex) and at high latitudes only in late winter (as a modulation of the timing of the final warming). This is true in both ERA-40 and CMAM. That the NH and SH winter vortices should respond differently to the QBO is perhaps due to the different climatological strengths of the two vortices and the different types of planetary waves that modulate them (Baldwin et al. 2001).

Distinct QBO phases appear to be associated with optimal early-winter and late-winter responses of the winter stratospheric polar vortex. This occurs in both the $\mathrm{NH}$ and the $\mathrm{SH}$, and in both ERA-40 and CMAM. While QBO influence in ERA-40 may be confounded with other influences such as climate forcing trends or interannual variations in SSTs (e.g., ENSO), no such influences exist in CMAM. Hence the similarities between CMAM and ERA-40 support the notion that the diagnosed seasonal variation of the vortex response in ERA-40 represents a fundamental aspect of QBO-vortex coupling rather than being an artifact of the shortness of the observed record. Further efforts to substantiate or disprove this conjecture would benefit from obtaining a more realistic QBO in CMAM, which is currently work in progress.

The vortex response in CMAM displays a similar pattern of development (i.e., seasonal progression of $\Delta \bar{u}$ patterns) as seen in ERA-40, although its amplitude tends to be weaker. The CMAM responses in January for the $\mathrm{NH}$ and in August-October for the SH have higher statistical significance than the corresponding ERA-40 responses. The choice of the $95 \%$ significance threshold used here to distinguish between "strong" and "weak" responses is of course arbitrary, and one cannot infer that just because high significance is not obtained for ERA-40 in these months that no real effect exists; only 
a longer observational record, or improved modeling studies, will resolve these ambiguities. The pattern of the CMAM responses is similar to that seen in ERA-40 despite the westerly bias of the CMAM QBO at altitudes below $25 \mathrm{~km}(30 \mathrm{hPa})$ noted in section 3. Thus, by accident of CMAM's unrealistic QBO, we may infer that realistic tropical winds below $25 \mathrm{~km}$ would not qualitatively alter the character of the response.

Because of the unrealistic vertical wavelength of the CMAM QBO, a comparison between CMAM and ERA-40 based on single-layer QBO phase groupings will yield misleading results. Use of the $50-\mathrm{hPa}(21 \mathrm{~km}) \mathrm{QBO}$ phase, as employed in numerous studies of the QBOvortex coupling, will in CMAM indicate a vortex response that appears to have the wrong sign and timing (not shown). This occurs because the relationship between $50-\mathrm{hPa} \mathrm{QBO}$ phase and the apparently causal altitudes is different in CMAM than for the observed QBO. The EOF method of section 4 provides a more useful means of comparing the model with measurements, which should be borne in mind when diagnosing QBO-vortex coupling in AGCMs that, like CMAM, have QBOs with unrealistic aspects.

Partial seasonal synchronization of QBO phase initiations occurs in CMAM, similar to behavior seen in tropical radiosonde data. As described in section 5, this suggests that decadal variations in the strength of QBOvortex correlations may be caused by internal atmospheric variability. One may construct a plot like Fig. 8, where instead of varying groupings of years based on $\psi$, the $t$ statistic is defined by the westerly-easterly composite difference when years are grouped into westerly QBO (QBO-W) and QBO-E categories defined by QBO winds at a particular altitude, and the horizontal axis represents the changing of that altitude. Constructing such plots separately for the 1958-78 and 1979-2001 periods (not shown) demonstrates substantial changes in $t$ during $\mathrm{NH}$ winter between the two periods, consistent with previously reported decadal variations in the strength of QBO-vortex correlations (Lu et al. 2008). A single-level QBO phase definition may obscure distinctions between QBO phases that are close in terms of $\psi$ but that differ in aspects that are dynamically significant for the extratropical response. Hence, it is possible that long-term (decadal) drifts of $\psi$ with respect to the annual cycle may alter the relationship between single QBO levels and the levels of causality, leading to single-level $t$ values being different in the two periods. That this happens in CMAM without any externally imposed interannual variability shows that it can happen from internal variability of the atmosphere. This provides an alternative explanation to apparent effects of the 11-yr solar cycle on QBO-vortex coupling.
Acknowledgments. The authors thank J. M. Wallace and D. B. Stephenson for useful discussions and Charles McLandress for his careful reading of the manuscript. This research has been supported by the Natural Sciences and Engineering Research Council and the Canadian Foundation for Climate and Atmospheric Sciences, through the C-SPARC network.

\section{REFERENCES}

Anstey, J. A., and T. G. Shepherd, 2008: Response of the northern stratospheric polar vortex to the seasonal alignment of QBO phase transitions. Geophys. Res. Lett., 35, L22810, doi:10.1029/ 2008 GL035721.

Baldwin, M. P., and T. J. Dunkerton, 1998: Quasi-biennial modulation of the Southern Hemisphere stratospheric polar vortex. Geophys. Res. Lett., 25, 3343-3346.

— , and — 1999: Propagation of the Arctic Oscillation from the stratosphere to the troposphere. J. Geophys. Res., 104, 30 937-30 946.

_ , and L. J. Gray, 2005: Tropical stratospheric zonal winds in ECMWF ERA-40 reanalysis, rocketsonde data, and rawinsonde data. Geophys. Res. Lett., 32, L09806, doi:10.1029/2004GL022328. - and Coauthors, 2001: The quasi-biennial oscillation. Rev. Geophys., 39, 179-229.

—, D. B. Stephenson, D. W. J. Thompson, T. J. Dunkerton, A. J. Charlton, and A. O'Neill, 2003: Stratospheric memory and skill of extended-range weather forecasts. Science, 301, 636-640.

Beagley, S. R., J. de Grandpré, J. N. Koshyk, N. A. McFarlane, and T. G. Shepherd, 1997: Radiative-dynamical climatology of the first-generation Canadian middle atmosphere model. Atmos.Ocean, 35, 293-331.

Bridger, A. F., 1984: A numerical test of connections between the stratospheric sudden warming and the quasi-biennial oscillation. J. Geophys. Res., 89, 4826-4832.

Calvo, N., M. A. Giorgetta, and C. Peña-Ortiz, 2007: Sensitivity of the boreal winter circulation in the middle atmosphere to the quasi-biennial oscillation in MAECHAM5 simulations. J. Geophys. Res., 112, D10124, doi:10.1029/2006JD007844.

Campbell, L. J., and T. G. Shepherd, 2005: Constraints on wave drag parameterization schemes for simulating the quasi-biennial oscillation. Part I: Gravity wave forcing. J. Atmos. Sci., 62, 4178-4195.

Chen, P., 1996: The influences of zonal flow on wave breaking and tropical-extratropical interaction in the lower stratosphere. J. Atmos. Sci., 53, 2379-2392.

Dunkerton, T. J., 1990: Annual variation of deseasonalized mean flow acceleration in the equatorial lower stratosphere. J. Meteor. Soc. Japan, 68, 499-508.

- 1997: The role of gravity waves in the quasi-biennial oscillation. J. Geophys. Res., 102, 26 053-26 076.

— planetary-wave fluxes in the Northern Hemisphere winter. J. Atmos. Sci., 48, 1043-1061.

Garcia, R. R., and S. Solomon, 1987: A possible relationship between interannual variability in Antarctic ozone and the quasibiennial oscillation. Geophys. Res. Lett., 14, 848-851.

Giorgetta, M. A., E. Manzini, E. Roeckner, M. Esch, and L. Bengtsson, 2006: Climatology and forcing of the quasi-biennial oscillation in the MAECHEM5 model. J. Climate, 19, 3882-3901.

Gray, L. J., 2003: The influence of the equatorial upper stratosphere on stratospheric sudden warmings. Geophys. Res. Lett., 30, 1166, doi:10.1029/2002GL016430. 
E. F. Drysdale, T. J. Dunkerton, and B. N. Lawrence, 2001a: Model studies of the interannual variability of the northernhemisphere stratospheric winter circulation: The role of the quasibiennial oscillation. Quart. J. Roy. Meteor. Soc., 127, 1413-1432.

—, S. J. Phipps, T. J. Dunkerton, M. P. Baldwin, E. F. Drysdale, and M. R. Allen, 2001b: A data study of the influence of the equatorial upper stratosphere on northern-hemisphere stratospheric sudden warmings. Quart. J. Roy. Meteor. Soc., 127, 1985-2003.

—, S. Sparrow, M. Juckes, A. O'Neill, and D. G. Andrews, 2003: Flow regimes in the winter stratosphere of the northern hemisphere. Quart. J. Roy. Meteor. Soc., 129, 925-945.

— S. Crooks, C. Pascoe, S. Sparrow, and M. Palmer, 2004: Solar and QBO influences on the timing of stratospheric sudden warmings. J. Atmos. Sci., 61, 2777-2796.

Hamilton, K., 1998: Effects of an imposed quasi-biennial oscillation in a comprehensive troposphere-stratosphere-mesosphere general circulation model. J. Atmos. Sci., 55, 2393-2418.

— - A. Hertzog, F. Vial, and G. Stenchikov, 2004: Longitudinal variation of the stratospheric quasi-biennial oscillation. $J$. Atmos. Sci., 61, 383-402.

Hampson, J., and P. Haynes, 2006: Influence of the equatorial QBO on the extratropical stratosphere. J. Atmos. Sci., 63, 936-951.

Hitchman, M. H., and A. S. Huesmann, 2009: Seasonal influence of the quasi-biennial oscillation on stratospheric jets and Rossby wave breaking. J. Atmos. Sci., 66, 935-946.

Holton, J. R., and H.-C. Tan, 1980: The influence of the equatorial quasi-biennial oscillation on the global circulation at $50 \mathrm{mb}$. J. Atmos. Sci., 37, 2200-2208.

_- and J. Austin, 1991: The influence of the equatorial QBO on sudden stratospheric warmings. J. Atmos. Sci., 48, 607-618.

Horinouchi, T., and S. Yoden, 1998: Wave-mean flow interaction associated with a QBO-like oscillation simulated in a simplified GCM. J. Atmos. Sci., 55, 502-526.

Huesmann, A. S., and M. H. Hitchman, 2001: The stratospheric quasi-biennial oscillation in the NCEP reanalyses: Climatological structures. J. Geophys. Res., 106, 11 859-11 874.

Karpetchko, A., and G. Nikulin, 2004: Influence of early winter upward wave activity flux on midwinter circulation in the stratosphere and troposphere. J. Climate, 17, 4443-4452.

Kodera, K., 1991: The solar and equatorial QBO influences on the stratospheric circulation during the early northern-hemisphere winter. Geophys. Res. Lett., 18, 1023-1026.

_- M. Chiba, and K. Shibata, 1991: A general circulation model study of the solar and QBO modulation of the stratospheric circulation during the northern hemisphere winter. Geophys. Res. Lett., 18, 1209-1212.

Labitzke, K., 1987: Sunspots, the QBO, and the stratospheric temperature in the north polar region. Geophys. Res. Lett., 14, 535-537.

— solar cycle, the QBO and the atmosphere. Part I: The troposphere and stratosphere in the northern hemisphere winter. J. Atmos. Terr. Phys., 50, 197-206.

Lindzen, R., and J. R. Holton, 1968: A theory of the quasi-biennial oscillation. J. Atmos. Sci., 25, 1095-1107.

Logan, J. A., and Coauthors, 2003: Quasibiennial oscillation in tropical ozone as revealed by ozonesondes and satellite data. J. Geophys. Res., 108, 4244, doi:10.1029/2002JD002170.

Lu, H., M. P. Baldwin, L. J. Gray, and M. J. Jarvis, 2008: Decadalscale changes in the effect of the QBO on the northern stratospheric polar vortex. J. Geophys. Res., 113, D10114, doi:10.1029/ 2007JD009647.
Maruyama, T., 1991: Annual and QBO-synchronized variations of lower-stratospheric equatorial wave activity over Singapore during 1961-1989. J. Meteor. Soc. Japan, 69, 219-231.

Matthes, K., U. Langematz, L. J. Gray, K. Kodera, and K. Labitzke, 2004: Improved 11-year solar signal in the Freie Universität Berlin Climate Middle Atmosphere Model (FUB-CMAM). J. Geophys. Res., 109, D06101, doi:10.1029/2003JD004012.

Naito, Y., and I. Hirota, 1997: Interannual variability of the northern winter stratospheric circulation related to the QBO and the solar cycle. J. Meteor. Soc. Japan, 75, 925-937.

, and S. Yoden, 2006: Behavior of planetary waves before and after stratospheric sudden warming events in several phase of the equatorial QBO. J. Atmos. Sci., 63, 1637-1649.

Naujokat, B., 1986: An update of the observed quasi-biennial oscillation of the stratospheric winds over the tropics. J. Atmos. Sci., 43, 1873-1877.

Niwano, M., and M. Takahashi, 1998: The influence of the equatorial QBO on the Northern Hemisphere winter circulation of a GCM. J. Meteor. Soc. Japan, 76, 453-461.

O'Sullivan, D., 1997: Interaction of extratropical Rossby waves with westerly quasi-biennial oscillation winds. J. Geophys. Res., 102, 19 461-19 469

— and M. L. Salby, 1990: Coupling of the quasi-biennial oscillation and the extratropical circulation in the stratosphere through planetary wave transport. J. Atmos. Sci., 47, 650-673.

_ , and R. E. Young, 1992: Modeling the quasi-biennial oscillation's effect on the winter stratospheric circulation. J. Atmos. Sci., 49, 2437-2448.

— , and T. J. Dunkerton, 1994: Seasonal development of the extratropical QBO in a numerical model of the middle atmosphere. J. Atmos. Sci., 51, 3706-3721.

Palmer, M. A., and L. J. Gray, 2005: Modeling the atmospheric response to solar irradiance changes using a GCM with a realistic QBO. Geophys. Res. Lett., 32, L24701, doi:10.1029/2005GL023809.

Pascoe, C. L., L. J. Gray, and A. A. Scaife, 2006: A GCM study of the influence of equatorial winds on the timing of sudden stratospheric warmings. Geophys. Res. Lett., 33, L06825, doi:10.1029/ 2005 GL024715.

Polvani, L. M., D. W. Waugh, and R. A. Plumb, 1995: On the subtropical edge of the stratospheric surf zone. J. Atmos. Sci., 52, 1288-1309.

Randel, W., and F. Wu, 1996: Isolation of the ozone QBO in SAGE II data by singular-value decomposition. J. Atmos. Sci., 53, 2546-2559. , and Coauthors, 2004: The SPARC intercomparison of middleatmosphere climatologies. J. Climate, 17, 986-1003.

Salby, M., and P. Callaghan, 2000: Connection between the solar cycle and the QBO: The missing link. J. Climate, 13, 328-338.

Scinocca, J. F., 2003: An accurate spectral nonorographic gravity wave drag parameterization for general circulation models. J. Atmos. Sci., 60, 667-682.

, N. A. McFarlane, M. Lazare, J. Li, and D. Plummer, 2008: The CCCma third generation AGCM and its extension into the middle atmosphere. Atmos. Chem. Phys., 8, 7055-7074.

Takahashi, M., 1996: Simulation of the stratospheric quasi-biennial oscillation using a general circulation model. Geophys. Res. Lett., 23, 661-664.

Uppala, S. M., and Coauthors, 2005: The ERA-40 re-analysis. Quart. J. Roy. Meteor. Soc., 131, 2961-3012.

von Storch, H., and F. R. Zwiers, 1999: Statistical Analysis in Climate Research. Cambridge University Press, 484 pp.

Wallace, J. M., R. L. Panetta, and J. Estberg, 1993: Representation of the equatorial stratospheric quasi-biennial oscillation in EOF phase space. J. Atmos. Sci., 50, 1751-1762. 